Discussion Paper No. 817

\title{
GENERALIZED HYPERBOLIC DISCOUNTING, BORROWING AVERSION, AND DEBT HOLDING
}

\author{
Shinsuke Ikeda \\ Myong-II Kang
}

October 2011

Revised October 2011

The Institute of Social and Economic Research

Osaka University

6-1 Mihogaoka, Ibaraki, Osaka 567-0047, Japan 


\title{
Generalized Hyperbolic Discounting, Borrowing Aversion, and Debt Holding*
}

\author{
Ikeda, Shinsuke ${ }^{* *}$ \\ and Myong-Il Kang ${ }^{* * *}$ \\ ISER, Osaka University \\ and \\ Department of Business Administration, Korea University \\ Korea University \\ ISER, Osaka University
}

29 Sep. 2011 ( $1^{\text {st }}$ version), 27 Oct. 2011 (this version)

\footnotetext{
* We are very grateful to D.J. Flath for helpful discussions. We would give thanks to K. Onoshiro for assistance. We appreciate financial supports from Grants-in-Aid for Scientific Research (B No. 21330046) from the Japan Society for the Promotion of Science and the 21 st COE Program and the Joint Usage/Research Center Project of ISER from the Ministry of Education, Culture, Sports, Science and Technology.

** Corresponding author: S. Ikeda, The Institute of Social and Economic Research, Osaka University, 6-1 Mihogaoka, Ibaraki, Osaka 567-0047, Japan. Telephone: 81-6-6879-8568, Fax: 81-6-6879-8583. E-mail: <ikeda@iser.osaka-u.ac.jp>.

${ }^{* * *}$ M. Kang, Department of Business Administration, Korea University, 1-700 Ogawa-cho, Kodaira, Tokyo 187-8560, Japan. Telephone: 81-42-341-1331. E-mail: <mkang@korea-u.ac.jp>
} 


\begin{abstract}
Analysis of an original, broad, internet-based survey reveals that debt holding is related to three aspects of time discounting: (i) present bias, measured by the degree of declining impatience in the generalized hyperbolic discount function; (ii) borrowing aversion, captured by a sign effect - discounting future losses at a lower rate than future gains; and (iii) impatience, measured by the overall discount rate. Present-biased respondents are classified as naïve if their answers reveal them to be time-inconsistent procrastinators, and classified as sophisticated otherwise. Naïve respondents with more steeply declining impatience are more likely to be debtors, and are likely to have larger amounts of debt, whereas sophisticates display only insignificant positive association between declining impatience and debt holding. Responses indicative of a sign effect are negatively associated with debt holding. The marginal effect on debt of such a sign effect is larger in magnitude than the effect of one standard deviation increases both in declining impatience and in impatience. Survey responses indicative of high or declining impatience are associated with high debt-to-income ratios, borrowing on credit cards, and the experiences of having borrowed unsecured consumer loans, of having engaged in debt-restructuring, or of having declared personal bankruptcy.
\end{abstract}

KEYWORDS: Debt; hyperbolic discounting; sign effect; naive; internet survey.

JEL Classification: D91, D14, D03. 


\section{Introduction}

We conduct an original nationwide internet survey of Japanese adults to empirically examine how debt behavior is related to personal time discounting. Our focus is on the association between debt behavior and three aspects of personal time discounting: (i) hyperbolic discounting or declining impatience, where a person is less patient in immediate future choices than in distant future choices (e.g., Thaler, 1981; Benzion et al., 1989; and Kinari et al., 2009); (ii) the sign effect, where a person discounts positive payoffs more intensely than negative payoffs (e.g., Khwaja et al. 2007; and Ikeda et al., 2010); and (iii) impatience, measured by the overall discount rate. In the internet survey, we ask respondents four hypothetical questions regarding intertemporal choices, which enables us to detect each respondent's time discounting biases, and to precisely infer each`s degree of impatience. We also ask detailed questions about their debt holdings, their credit history, and their economic status.

Intertemporal choice theory predicts that time discounting affects borrowing through three channels. In the classic microeconomic framework, impatience, measured by time preference, is an important determinant of consumers' saving and borrowing (e.g., Fisher, 1930). In the more recently developed behavioral economics framework, hyperbolic discounting (or declining impatience) and the resulting self-control problem are predicted to cause overconsumption, undersaving and overborrowing (e.g., Laibson, 1996, 1997; Krusell et al., 2002; Laibson et al., 2003, 2007). Also the behavioral economics predicts that gain-loss asymmetry in time discounting, captured by the sign effect, makes consumers averse to intertemporal trades, and hence leads to "borrowing aversion" (Loewenstein and Prelec, 1992). In sum, theory predicts that indebtedness has positive association with hyperbolic discounting and impatience and negative association with the sign effect. Although the theoretical predictions are logical and testable, there have been few attempts at direct empirical confirmation.

The contribution of our research is to directly and systematically measure associations between time discounting and borrowing behavior. In so doing, we add three novelties. First, we specify the discount factor in the form of a "generalized hyperbolic discount function" (Loewenstein and Prelec, 1992), which is characterized by two parameters. One parameter indicates the degree of hyperbolic deviation from exponential discounting $(\alpha)$ and the other determines the intercept $(\eta)$. We adduce the two parameters for 
each individual from responses to hypothetical questions regarding immediate future choices and distant future choices. Each individual's $\alpha$ value measures his degree of declining impatience. We find that this measure is associated with debt behavior in the way predicted. The inferred individual values of parameter $\eta$ are combined with other discount rates to construct each's degree of impatience.

Second, we distinguish the naïve, who do not expect that as time passes their impatience for given points in the future is going to rise, and the sophisticated, who correctly anticipate the future incidence of their own preference reversals and behave consistently with what their future impatient "selves" would do. Theory predicts that naïve hyperbolically discounting consumers display time-inconsistent overborrowing, whereas sophisticated people may somehow forestall their own undesirable inclination to overborrow. ${ }^{1}$ To examine the validity of the theoretical predictions, we ask respondents two questions regarding their behavioral tendencies. The one is how likely they were in fact to procrastinate by putting off doing onerous homework assignments during vacations in their school days. The other is how late they planned to do the same homework assignments at that time. Using the response data, we divide hyperbolic respondents into naïve ones, who self-reported unplanned procrastination, and sophisticated ones, who did not. We show how the effect of hyperbolic discounting on debt holdings depends on whether the respondent is naïve or sophisticated.

Third, we examine association between time discounting and inclination toward overborrowing, which is revealed by high debt-to-income ratios, borrowing on credit cards, and the experiences of having borrowed unsecured consumer loans, of having being denied a loan, of having engaged in debt-restructuring, or of having declared personal bankruptcy.

We first find that, for the naïve respondents, both debt holding and overborrowing inclination are associated positively with the degree of declining impatience. For example, for the naïve respondents, an increase in the degree of declining impatience by one standard deviation leads to: a 3.6 percentage-point higher probability of being a debtor; a 2.1 percentage-point higher probability of having credit-card debts;

1 See, e.g., Phelps and Pollack (1968), O'Donophue and Rabin (1999), and Heidhue and Kőszegi (2010). As noted by these theoretical works, however, being sophisticated can affect saving and borrowing in either direction, i.e., it can either mitigate or exaggerate the undersaving and overborrowing problems that naïve people would face. 
and a JPY0.10 million (USD1,233) larger debt amount. Notably, the marginal effect on the likelihood of having credit card debts is not that small compared with the prevalence rate of credit-card debtors in the sample (8.6\%). In contrast, the sample of the sophisticated respondents displays only insignificant positive association between declining impatience and borrowing. This implies that being sophisticated significantly weakens the positive association between declining impatience and debt holding.

We also find that borrowing aversion, revealed by the incidence of the sign effect, negatively relates to actual debt holding, as predicted by Loewenstein and Prelec (1992). The probability of respondents who are subject to the sign effect being indebted is 6.1 percentage-points lower than the corresponding probability for those who are not subject to the effect. The marginal effect of the presence of the sign effect on the respondents' debt amount is JPY0.24 million (USD2,959). These marginal effects of the presence of the sign effect are all larger than the marginal effect of a one-standard-deviation increase both in the degree of declining impatience and in the degree of impatience.

The degree of impatience, measured by the discount rate, positively relates not only to debt holding but also to overborrowing inclination. A one-standard-deviation increase in impatience leads to: a 5.4 percentage-point higher probability of being a debtor; a JPY0.18 million (USD2,219) larger amount of debt; and a 2.2 percentage-point higher probability of having credit card debts.

The robustness of the regression results are checked in two ways. First, regressions are re-conducted by using for a regressor the present bias dummy, instead of the degree of declining impatience. Second, to rule out the possibility that our results simply reflect that responses indicative of present bias or high discount rates are a consequence of overborrowing rather than the cause of it, we re-estimate debt equations by excluding from the sample any respondent with a credit problem or a troubled credit history. Our results are robust against these considerations.

This research relates to the previous literature as follows. By calibration, Angeletos et al. (2001) and Laibson et al. (2003) show that the model of hyperbolic discounting consumers has the potential of resolving "the debt puzzle" that over $60 \%$ of US households are borrowing on credit cards. Using micro data provided by payday lenders, Skiba and Tobacman (2008) analyze the behavior of payday-loan borrowers by Method of Simulated Moments to accept partially-naïve hyperbolic-discounting models. These studies successfully present indirect evidence that hyperbolic discounting relates to (over)borrowing. 
The evidence, however, is not based on micro data of personal discount rates.

Meier and Sprenger (2010) report that debt levels on revolving accounts have positive correlation with present bias. The study is important especially because they match credit bureau data of actual debt holding and the discount-rate data elicited using choice experiments. Our debt data are self-reported and thus possibly contain under-reporting bias. Nevertheless, if we detect positive correlation between present bias (or declining impatience) and debt, true association can be regarded as also positive insofar as the underreporting of debt is not negatively correlated with the present bias. Although our study is similar in spirit to Meier and Sprenger's, we add new insights by controlling for whether the respondents are naïve or sophisticated and by incorporating the degree of declining impatience and the sign effect. ${ }^{2}$

The sign effect has been shown to relate negatively to smoking (Khwaja et al., 2007; and Kang and Ikeda, 2011) and to obesity (Ikeda et al. 2010). Although Ikeda et al. (2010) also report negative association between the incidence of the sign effect and debt holding, neither hyperbolic discounting nor sophistication is controlled for in the regression analysis.

Our way of identifying the naïve and the sophisticated is similar to that of Wong (2008). He identifies whether in his class on macroeconomics are subject to the self-control problem and how naïve the students with self-control problem might be by asking them three questions: (i) when they should ideally start

${ }^{2}$ See also Ottaviani and Vandone (2011), which reports significant associations between impulsivity and unsecured debt holding. A similar association to theirs is detected for here in an economic model with present bias and other discounting factors. By estimating a simple hyperbolic discount function from a laboratory task experiment, Chabris et al. (2009) show that individuals' elicited "discount rates" predict inter-individual variations in various field behaviors, including credit-card debt holding. However, their focus is not on debt but rather on health-related behaviors. They do not distinguish the overall discount rate and present bias nor control for the degree of naiveté or for the sign effect. Tsutsui et al. (2007) discussed on associations between time discounting and debt behavior using cross-section data. Using panel survey data, Ikeda et al. (2010) show that the effect on debt holding of an exogenous reduction in the usury cap, which was brought about by Japan's supreme-court decision in 2009, depends on the debtor's procrastinating tendency, a proxy of present bias. See also Tanaka and Murooka (2010), which provides a comprehensive survey on consumption-saving decisions under the self control problem. 
midterm preparation; (ii) knowing themselves, when they themselves predict to start it, whatever the ideal action may be; and (iii) when they actually did start it. By matching these self-reported data to the students' actual grades, he shows that the time inconsistency problem and naiveté negatively affect both actual class performance and final grade. By applying this simple idea, where our couple of questions on when to do onerous homework assignments can be regarded as corresponding to Wong's questions (ii) and (iii), we work out differences in borrowing behavior between naïve respondents and sophisticated ones.

The remainder of the paper is structured as follows. In Section 2, the theoretical relation between time discounting and debt holding behavior is briefly discussed. Section 3 explains the data. Section 4 shows the regression results. Section 5 checks the robustness of the results. Section 6 concludes the paper.

\section{Time discounting and debt holding behavior}

When we make intertemporal consumption decisions, the subjective discount rate or time preference, as a measure of impatience, plays a key role in determining how much resource is consumed for present gratifications, and saved for future gratifications. We hypothesize that debt holding is, in part, related to time discounting. To detect for the association between time discounting and debt holding, we focus on three aspects of time discounting: (i) hyperbolic discounting, (ii) the sign effect, and (iii) impatience. In this section, we first demonstrate theoretical backgrounds of our empirical analysis.

\subsection{Hyperbolic discounting and impatience}

Consider consumers whose discount factor for future felicity with delay $\tau$ is given by the generalized hyperbolic discount function $f(\tau)$ :

$$
f(\tau ; \alpha, \eta)=(1+\alpha \tau)^{-\eta}, \tau \geq 0, \alpha \geq 0, \eta \geq 0
$$

The discount rate $\rho$, which is obtained by computing $-f^{\prime}(\tau) / f(\tau)$, is given as:

$$
\rho(\tau ; \alpha, \eta)=\frac{\alpha \eta}{1+\alpha \tau}
$$

In (2), three points are noteworthy. First of all, the discount rate is declining in delay $\tau$, which 
represents the usual property (e.g., Ainslie, 2001; and Benzion et al., 1989) of hyperbolic discounters that they are less patient in immediate future choices than in distant future choices. Secondly, the degree of declining impatience is higher as $\alpha$ is larger. Especially, for two distinct delays $\tau_{1}$ and $\tau_{2}\left(\tau_{1}>\tau_{2}\right)$, the relative discount rates $\rho\left(\tau_{1}\right) / \rho\left(\tau_{2}\right)\left(=\left(1+\alpha \tau_{2}\right) /\left(1+\alpha \tau_{1}\right)\right)$, which are smaller than one, depends solely on $\alpha$ : a large $\alpha$ implies a small $\rho\left(\tau_{1}\right) / \rho\left(\tau_{2}\right)$. We thus refer to $\alpha$ as the degree of declining impatience. Thirdly, the discount rate equals $\alpha \eta$ when $\tau=0$, which implies that, for given $\alpha, \eta$ determines the discount rate for infinitesimally short horizon. For given $\alpha$ and $\tau$, the discount rate $\rho$ has the same information as $\eta$. To ease interpretation, and from the data availability, we focus on the relationship of debt behavior and $(\alpha, \rho)$, rather than $(\alpha, \eta)$. The discount factor depends negatively on both declining impatience $\alpha$ and impatience $\rho .^{3}$ The positive association between impatience and debt holding follows from the standard theory of intertemporal choice (e.g., Fisher, 1930).

As for the effect of declining impatience, we should consider whether the hyperbolic discounter is a naïve person, who do not expect that, as time passes, their impatience is going to rise, and hence that the preference reversal will take place, or a sophisticated one, who expects correctly the future incidence of the preference reversal and behaves consistently with what future impatient "selves" would do (see, O'Donophue and Rabin, 1999).

With declining impatience, hyperbolic discounters face a self-control problem: "selves" in different points in time always have weaker preferences toward immediate savings than they would have toward future savings. When they are naïve, the declining impatience causes overconsumption, undersaving, and overborrowing in a time-inconsistent way. Thus, for naïve hyperbolic discounters, debt holdings are expected to depend positively on the degree of declining impatience $(\alpha)$.

When hyperbolic discounters are sophisticated, it may be plausible to hypothesize that the positive effect of declining impatience on undersaving and overborrowing becomes somewhat weaker than it would be if they were naïve. It is true firstly because, if the agent is sufficiently risk-averse, the present "self" has

${ }^{3}$ When we rewrite $f(\tau ; \alpha, \eta)$ as $F(\tau, \alpha, \rho(\tau ; \alpha, \eta))$, the discount factor $F$ satisfies $\partial F(\tau, \alpha, \rho) / \partial \tau=f_{\tau}<0$, $\partial F(\tau, \alpha, \rho) / \partial \alpha=f_{\alpha}<0$, and $\partial F(\tau, \alpha, \rho) / \partial \rho=((1+\alpha \tau) / \alpha) f_{\eta}<0$. 
a saving incentive for future selves as to retain their consumption levels. ${ }^{4}$ Secondly, sophisticates have an incentive to commit to his lifetime consumption plan by using some devices (e.g., illiquidity assets, savings accounts, 401(k), not using credit cards, etc.). In that case, they can prevent future selves from overconsuming and overborrowing due to the preference reversal (see Laibson, 1995; Sourdin, 2008). ${ }^{5}$

In sum, we hypothesize the followings regarding the relationships between the debt holding behavior and $(\alpha, \rho)$ :

H1 The degree of impatience, measured by the discount rate $\rho$, positively relates to debt holding.

H2 For naïve respondents, the degree of declining impatience, measured by $\alpha$, positively relates to debt holding and overborrowing inclination.

H3 For sophisticated respondents, positive association between the degree of declining impatience and debt holding is somewhat weaker than for the naïve.

\subsection{The sign effect}

Behavioral economists have reported that losses are discounted at a lower rate than gains. For example, Thaler (1981) elicited discount rates for gains that were three to ten times higher than those for losses. Several of his subjects revealed negative discount rates for loss, which implying that an immediate loss is preferred to a delayed loss of the same value. Loewenstein (1988) reported that, for his subjects, receiving USD 100 today was indifferent to receiving USD 157 in a year, whereas loosing USD 100 immediately was indifferent to USD 133. This prevalent gain-loss asymmetry is referred to as the sign effect (Frederick,

4 In the literature (e.g., Phelps and Pollack, 1968; and O'Donophue and Rabin, 1999), it is known that being sophisticated, rather than naïve, mitigates the self-control problem and undersaving if the utility function is more concave than the log utility. As is known in the empirical studies on the equility premium puzzle, actual estimates of the relative risk aversion parameter are usually much higher than one. Being sophisticated is thus considered to mitigate, rather than exaggerate, the undersaving behavior of the naïve.

${ }^{5}$ In Appendix A, consumption/borrowing behavior of the naïve and the sophisticated under generalized hyperbolic discounting are discussed formally by using a three-period model. 
et al., 2002).

With the sign effect, people are reluctant to intertemporal trade-offs, which causes aversion to both lending, i.e., giving up a part of present consumption for future consumption, and borrowing, i.e., giving up a part of future consumption for present consumption. Loewenstein and Prelec (1992) show analytically the property by using a "temporal prospect" model. We hypothesize that respondents whose time preferences display the sign effect are likely to hold smaller debt. ${ }^{6}$

H4 The incidence of the sign effect negatively relates to debt holding and overborrowing.

\section{The data}

Our empirical research is based on our original nationwide internet survey, titled as the Japan Internet Survey on Preferences Relating to Time and Risk 2010 (hereafter JPTR 2010). Nikkei Research, Inc., a representative Japanese private research company, which deals with economic surveys to construct database for academic and non-academic purposes, carried out the survey during October 21 to 27, 2010, by using questionnaires that we prepared. The respondents were 2387 Japanese people between the ages of 20 and 65, who had been enrolled in the Nikkei Research Access Panel, which was composed totally of

\footnotetext{
${ }^{6}$ The temporal prospect model of Loewenstein and Prelec (1992) describes choices among sequences of dated adjustments to consumption, rather than the entire lifetime utility maximization problem. Although there is no theoretical discussions on the issue, one simple way to incorporate the sign effect into the entire lifetime utility maximization problem is to assume that there is an exogenous reference consumption level $\overline{\mathrm{c}}$ and to specify the discount factor for period utility $u\left(c_{\tau^{-}} \bar{c}\right)$ with delay $\tau, u\left(c_{\tau^{-}} \bar{c}\right)$, as

$$
g(\tau)=(1+k \theta) f(\tau)
$$

where, with $\theta$ denoting a binary indicator which takes one for $c_{\tau}<\bar{c}$ and zero otherwise, $k(>0)$ represents the sign effect, which weakens time discounting when $c_{\tau}$ is smaller than the reference level $\bar{c}$; and $f(\tau)$ is the discount factor in (1). When $\bar{c}<$ current total income $y_{\tau}, c_{\tau}<\bar{c}$ implies $c_{\tau}<y_{\tau}$ and hence borrowing $c_{\tau}-y_{\tau}$ is positive. It follows that consumers apply lower discount rates when choosing how much to borrow.
} 
about 155,000 registrants. $^{7}$ Cash voucher are provided as incentives by lottery to respondents. The sample was selected by stratified random sampling such that the age and sex distribution is as close as possible to that of the Japanese census. We included various questions in the survey to elicit information about: the respondents' preferences regarding time discounting and risk aversion; ${ }^{8}$ their economic attributes, including debt holding behavior, income, and asset holding; and demographic and social attributes.

The summary statistics of background attributes of the respondents are listed in panel A of Table 1. Males occupied $49.9 \%$ of the respondents with the average age of 41.8 .

\section{Insert Table 1. Summary statistics}

\subsection{Debt}

In JPTR 2010, we asked respondents to indicate how much they had debt other than mortgages by choosing one of nine ranges, from (1) "no debt" to (9) "more than JPY 10 million." To construct the data of debt amounts, we assign median to each of the nine individual ranges that the respondents chose. ${ }^{9}$ As seen from panel B of Table 1, around a $20.2 \%$ of the respondents have debts, the average of which amounts to JPY 2.45 million (converted to around USD 30,265 by the average yen/dollar rate (81.1) in October 2011). ${ }^{10}$

\footnotetext{
${ }^{7}$ During the survey period of October 21 to 27, 2010, 11,090 registrants were notified about the survey by e-mail. During October 5 to 12, 2010, we conducted a pre-survey, in which 177 responses were collected from 902 samples sent. The sample of the pre-survey was excluded from the main survey.

${ }^{8}$ To elicit the degree of risk aversion, we asked respondents to make sequential three binary choices, as in Figure A1 of Appendix B for discount rates, on whether they buy lottery "A" that gives JPY100,000 (USD1233) with probability 0.5 at given prices, specified as JPY10 to JPY50,000.

${ }^{9}$ As for the highest range (9): "more than JPY 10 million", we simply take it as [JPY 10 million, 12.5 million), where the width of JPY 2.5 million is determined such that it equals to the width of the range of (8): [JPY 7.5 million, JPY 10 million).

${ }^{10}$ Hereafter we use the conversion rate (81.1 JPY/USD) when converting JPY values into USD values.
} 
We also asked the respondents with debts to indicate for what purposes they borrowed, from seven options (multiple responses are allowed): (i) purchasing cars; (ii) purchasing other goods; (iii) financing living costs; (iv) financing business activities, (v) financing amusements, (vi) paying off other debts; and (vii) others. Debts for cars $(6.6 \%)$, other goods $(8.0 \%)$, and living costs $(4.1 \%)$ are relatively frequent among the seven (see panel B of Table 1).

To quantify the respondents' inclination toward overborrowing, we construct an excess debt indicator which equals one if the debt amount held is larger than $30 \%$ of annual household income, and zero otherwise. ${ }^{11}$ As seen in panel B of Table 1, excess borrowers in this sense amount to $8.1 \%$ in the sample. Besides, we asked all the respondents: (i) whether or not they have credit-card debt including debt on a revolving-payment account; (ii) whether or not they have ever borrowed unsecured consumer loans; (iii) whether or not they have ever been denied a loan for whatever reason; and (iv) whether or not they have ever engaged in (out-of-court) debt-restructuring, or declared personal bankruptcy.

As seen from the table, credit-card debtors occupy only $8.6 \%$ in the sample, which is much smaller than in the U.S. case. For example, based on the actual credit report data from the U.S. credit bureaus, Meier and Sprenger (2010) report that $41 \%$ of their 541 respondents have credit-card debts on revolving accounts. Similarly, the rate of respondents who have ever borrowed unsecured consumer loans $(8.7 \%)$ and that of respondents who have experienced debt-restructuring or personal bankruptcy $(2.1 \%)$ are not high. As conjectured from the finding of Karlan and Zinman (2006) that nearly a half of their respondents underreported borrowing of high interest consumer loans, our self-reported data may contain underreporting bias. Notwithstanding the concerns about possible self-reporting bias, we shall use the self-reported data because of limited data availability. This may be a limit of our empirical study. But note that if we detect positive association between present bias (or impatience) and debt, then actual association can also be taken as positive so long as underreporting of debt is not negatively associated with present bias (or impatience). ${ }^{12}$

\footnotetext{
${ }^{11}$ In June, 2010, the Japanese government revised the Money Lending Business Control Law to ban individuals from newly borrowing when the outstanding amounts of their debts exceed one third of their annual income.

12 To see this, suppose first that underreporting of debt is independent of time discounting. Then,
} 


\subsection{Time discounting}

In the survey, we try to elicit the respondents' time discounting using four questions on intertemporal choice: two (Q1 and Q2) are designed to detect the degree of declining impatience ( $\alpha$ ); and the other two (Q5 and Q6) are to detect the incidence of the sign effect $(\theta)$. We also measured the degree of impatience ( $\rho$ ) from their responses to the four questions.

As noted in the literature (e.g., Frederick et al., 2002; and Anderson et al., 2008), the discount rate will be overestimated unless the effect of the curvature (risk aversion) of the utility function is controlled. Nevertheless, to make it easier to calculate the parameters of the generalized hyperbolic discount function, we do not control for the effect of risk aversion in eliciting the personal discount rates. Instead, we cope with the problem in two ways. First, when estimating association between time discounting and debt by regression, we incorporate as a control variable the degree of risk aversion which is inferred from responses to a query on risky choice. Then, the estimated coefficients of time discounting variables represent partial correlation after controlling for the effects of risk aversion both on time discounting and on debt. Secondly, we will also conduct regression later by using for a regressor the binary indicator for present bias $(\alpha>0)$, instead of the degree of declining impatience $(\alpha)$ itself. As the value of the binary indicator for present bias is not affected by the degree of risk aversion (see Eisenhauer and Ventura, 2006), the reexamination would work as a robustness check.

\subsubsection{Declining impatience}

estimated association, if detected, between time discounting and debt behavior can be taken as the unbiased estimate of true association. Next, suppose instead that underreporting of debt is positively associated with present bias, i.e., that hyperbolic respondents are more likely to underreport debt than exponential ones. Then association between present bias and debt would be underestimated (or overestimated) if true association is positive (or negative). Therefore, if positive association is detected from the self-reported data, it implies that true association is also positive. 
Questions Q1 and Q2 consist of sequential three binary decisions on immediate future trade-offs and of distant future trade-offs, respectively. As illustrated in Appendix B, in Q1, respondents are asked to choose between: (A) getting JPY 1,000 (around USD 12.3) today; and (B) getting JPY 1,000 plus a certain amount a week later; whereas in Q2 the options are: (A) getting JPY 1,000 a year later; and (B) getting JPY 1,000 plus a certain amount a year plus one week later. Let $X_{Q_{1}}$ and $X_{Q 2}$ be the delayed money amounts in Q1 and Q2, respectively, which are taken as subjectively equivalent to JPY 1,000 in options (A). Then, the degree of declining impatience $\alpha$ in (1) is obtained by solving jointly

$$
\begin{aligned}
1000 & =X_{Q 1} f(7, \alpha, \eta), \\
1000 f(365, \alpha, \eta) & =X_{Q 2} f(372, \alpha, \eta),
\end{aligned}
$$

which are combined to a non-linear equation of $\alpha$,

$$
\frac{\ln (1000)-\ln \left(X_{Q 1}\right)}{\ln (1000)-\ln \left(X_{Q 2}\right)}=\frac{\ln (1+7 \alpha)}{\ln (1+365 \alpha)-\ln (1+372 \alpha)}
$$

In Table 2, panel A summarizes elicited parameters which characterize the generalized hyperbolic discount function. Note that a positive $\alpha$ implies declining impatience or present biased preferences. The sample mean of $\alpha$ equals 0.018 , which differs significantly from zero $(p<0.00)$. The average respondents are thus present biased $(\alpha>0)$. A $40.1 \%(N=960)$ of the 2386 respondents are present-biased (see Table 3 below). ${ }^{13}$

\section{Insert Table 2.}

By substituting the sample mean of $(\alpha, \eta)$ into (2), Figure 1 illustrates the discount rates of the average respondent, the average debtor, and the average non-debtor, as decreasing functions of delay $\tau$. As is also shown in panel A of Table 2, the debtor's discount rate schedule is characterized by its stronger concavity

13 The rate of present biased respondents is comparable with that which Meier and Sprenger (2010) estimate for the US sample (36\%), and is somewhat higher than that which Eisenhauer and Ventura (2006) report (22.8\% for the Italian sample and $18.4 \%$ for the Dutch sample). 
(i.e., a larger $\alpha$ ) and higher intercept (i.e., a larger $\alpha \eta$ ).

\section{Insert Figure 1.}

\subsubsection{Naïve or sophisticated}

To identify whether each of the hyperbolic respondents is naïve or sophisticated, we asked two queries Q3 and Q4 as to: (i) how early used to do homework assignments during school vacation; and (ii) how early to finish up homework assignments used to plan during school vacation, respectively:

Q3 Thinking about when you were a child and you were given an assignment during school vacation, how early did you usually finish up the assignment? (X ONE Box)

1 Got it done right away.

2 Tended to get it done early, before the due date.

3 Worked on it daily up until the due date.

4 Tended to get it done toward the end.

5 Got it done at the last minute.

Q4 Thinking about when you were a child and you were given an assignment during school vacation, how early to finish up did you plan for the assignment? (X ONE Box)

1 I planned to get it done right away.

2 I planned to get it done rather early, before the due date.

3 I planned to work on it daily up until the due date.

4 I planned to get it done rather toward the end.

5 I planned to get it done at the last minute.

$6 \quad$ I didn't make any plans.

After excluding 109 hyperbolic respondents who did not make any plans (i.e., who chose "6" in Q4) 
from the sample, we take present-biased respondents (i.e., those with $\alpha>0$ ) who chose a larger number in Q3 than in Q4 as being naïve, because they could be regarded as those who were not cognizant of their self-control problem and tended to procrastinate onerous jobs in a time-inconsistent way. The other respondents, who are non-hyperbolic $(\alpha \leq 0)$ or did choose a weakly smaller number in Q3 than in Q4, are identified as being sophisticated. The naïve ( $N=576)$ occupy $60.0 \%$ of 960 hyperbolic respondents who used to make plans over performing assignments. ${ }^{14}$

\subsubsection{The sign effect}

To detect the sign effect, we elicit the discount rates for future receipts and future payments by asking queries Q5 and Q6, respectively. In doing so, we follow the literature (e.g., Harrison et al., 2002) in asking respondents to make nine of binary decisions in each of two payoff tables, where the money amounts with front-end delay are commonly set to JPY 1 million (around USD 12,330). See Appendix C for the payoff table of Q6.

As summarized in panel B of Table 2, the sample mean of the discount rates for future receipt, elicited from Q5, is $8.8 \%$, whereas that of the discount rates for future payments, elicited from Q6, is $0.1 \%$. The difference of the two means is highly significant $(p<0.000)$. The average respondent thus displays the sign effect. The proportion of the respondents who exhibited the sign effect $(N=1859)$ amounts to $81.1 \%$.

\subsubsection{Impatience}

We quantify each respondent's degree of impatience by taking the standardized average of the four

${ }^{14}$ The proportion of the naïve might be underestimated because in Q4 and Q5 the respondents might self-report their past behavior as more rational and time-consistent than it actually were. For example, the proportion of the naïve is comparable with, but somewhat smaller than, what Wong (2008) shows by conducting a field survey in the university class on macroeconomics. In his sample, naïve subjects occupy $86.4 \%$ of the students with the time-inconsistency problem in actual midterm preparation. See also Hey and Lotito (2009), which estimates by conducting experiments.that $50 \%$ of their subjects are naïve. 
discount rates that are implied from queries Q1, Q2, Q5, and Q6: Two are discount rates for $\tau=7$ and 372 elicited from Q1 and Q2, i.e., $\rho(7)$ and $\rho(372)$ computed from (2); and the other two are the discount rates for future receipts and payments implied from Q5 and Q6. ${ }^{15}$

\section{Results}

\subsection{Means in stratified sample}

Let us start with examining simple associations between time discounting and debt behavior. Panel B of Table 3 compares average debt behavior among respondents stratified by whether their impatience is declining $(\alpha>0)$ or not $(\alpha \leq 0)$; whether impatience $\rho$ is higher than the average or not; and whether the sign effect is present $(\theta=1)$ or not $(\theta=0)$. The table shows that debt holding and time discounting are associated consistently with our hypotheses H1 to H4. First, naïve respondents with a positive $\alpha$ are more likely to be debtors and have larger amounts of debt than both sophisticated hyperbolic respondents and non-hyperbolic respondents. Both associations are significant. For example, in the sample of the naïve, the proportion of debtors is $23.8 \%$, which is higher than $20.3 \%$ in the sample of the hyperbolically sophisticated and $18.1 \%$ in the non-hyperbolic sample. For all the overborrowing indices ("Debt-to-income ratio $>30 \%$ " to "Having ever engaged in debt restructuring or declared personal bankruptcy"), respondents with overborrowing inclination occupy larger proportions in the naïve sample than both in the sophisticated sample and in the non-hyperbolic sample $(\alpha \leq 0)$. The associations are all significant.

\section{Insert Table 3.}

Secondly, in all the cases, less patient respondents $(\rho>$ mean) display stronger inclinations toward borrowing and overborrowing than the more patient. For example, the average debt amount of the high- $\rho$

\footnotetext{
${ }^{15}$ Note that $\rho(7)$ and $\rho(372)$ are daily discount rates while the discount rates implied from Q5 and Q6 are expressed in annual rates. As we standardize the rates, this difference does not matter when computing the average of the four rates.
} 
respondents (JPY 0.73 million) is around twice as large as that of the low- $\rho$ respondents (JPY 0.37 million). In the sample of the high- $\rho$ respondents, the proportion of the respondents who have the experience of having engaged in debt restructuring and/or declared personal personal bankruptcy (3.8\%) is nearly three times as high as that in the low- $\rho$ sample (1.3\%). Except that the difference in average debt amounts between high- and low-respondents is insignificant for the debtor sample, the positive associations between (over)borrowing and impatience are significant.

Thirdly, the incidence of the sign effect is shown to be associated with borrowing aversion, as expected. For example, debtors occupy $18.9 \%$ in the sample with the sign effect, whereas they do $23.4 \%$ in the sample without the sign effect. However, the negative correlation between overborrowing and the sign effect is not valid except for "Debt-to-income ratio $>30 \% "$.

\subsection{Regression results}

\subsubsection{Debt holding}

To detect associations between debt holding behavior and each of three time-discounting variables $(\alpha, \rho, \theta)$, we estimate models (A) and (B). In model (B), the product term of declining impatience $(\alpha)$ and the dummy variable for the naïve $\left(D_{N}\right)$ is added to the set of independent variables. In both models, control variables for other personal attributes are included. The controls include: (i) the degree of risk aversion; (ii) demographic factors, including age, gender, and education; and (iii) economic factors, including household income, household real asset holding, and household financial asset holding.

For example, letting Debtor $_{i}$ represent a binary indicator which equals one if the respondent $i$ is a debtor, and zero otherwise, we estimate the probability that respondent $i$ with time discounting attributes $\left(\alpha_{i}, \rho_{i}, \theta_{i}\right)$ and controlled attributes $x_{i}$ is a debtor by using probit models (A) and (B):

$$
\begin{aligned}
& \operatorname{Pr}\left(\text { Debtor }_{i}=1 \mid \alpha_{i}, \rho_{i}, \theta_{i}, x_{i}\right) \\
& =\left\{\begin{array}{cc}
\Phi\left(c+\beta_{\alpha} \alpha_{i}+\beta_{\rho} \rho_{i}+\beta_{\theta} \theta_{i}+\not x_{i}\right) & \text { for model (A), } \\
\Phi\left(c+\beta_{\alpha} \alpha_{i}+\beta_{N} \alpha_{i} D_{N i}+\beta_{\rho} \rho_{i}+\beta_{\theta} \theta_{i}+\not x_{i}\right) & \text { for model (B). }
\end{array}\right.
\end{aligned}
$$

where $\Phi$ represents the cumulative normal distribution. In the specification of model (B), with the product term $\alpha_{i} * D_{N i}$ being added, coefficient $\beta_{\alpha}$ captures correlation for sophisticated respondents between the 
likelihood of being a debtor and $\alpha_{i}$, whereas the corresponding correlation for the naïve are given by $\beta_{\alpha}+\beta_{N}$.

We also estimate the debt holding function by using debt amounts for the dependent variable. In so doing, the interval tobit regression model is estimated, because the debt amount data are right-censored at zero.

Panel A of Table 4 summarizes the marginal effects of increases in declining impatience $(\alpha)$, impatience $(\rho)$, and the sign effect $(\theta)$ on the probability of being a debtor and on the amount of debt holding. As we shall explain below in order, we can confirm that our hypotheses $\mathrm{H} 1$ to $\mathrm{H} 4$ are supported at high significance levels.

\section{Insert Table 4.}

As consistent with $\mathrm{H} 1$ and $\mathrm{H} 2$ (i.e., the hypotheses concerning associations between $\alpha$ and debt holding of the naïve/sophisticated), the results of model (B) show that, for naïve respondents, declining impatience has positive correlations with both the probability of being a debtor and the amounts of debt holding, whereas, for sophisticated respondents, the corresponding correlations are insignificant. Either for the probability of being a debtor or for the amounts of debt holding, associations between $\alpha$ and debt holding differ between the naïve and sophisticated respondents at the $10 \%$ significance level (not listed in the table). Quantitatively, for naïve respondents, an increase in $\alpha$ by one unit of standard deviation $(0.046)$ leads to: (i) a 3.6 percentage-point $(=0.046 * 0.780)$ higher probability of being a debtor; (ii) a JPY 0.10 $(=0.046 * 2.12)$ million larger debt amount of respondents; and (iii) a JPY $0.12(=0.046 * 2.61)$ million larger debt amount of debtors.

Positive association between impatience ( $\rho$ ) and debt holding (i.e., H3) can also be confirmed at high significance levels. With other personal attributes being equal, respondents who are less patient by one unit of standard deviation than the average: (i) are debtors with a 5.4 (or 5.5) percentage-point higher probability in model (A) (or (B)); and (ii) have a JPY 0.22 (or 0.23) million larger amount of debt in model (A) (or (B)) for the debtor sample.

As predicted by $\mathrm{H} 4$, the respondents' debt holding has strong negative correlations with the incidence of the sign effect. The probability of respondents who are not subject to the sign effect being indebted is 
6.3 (6.1) percentage-points higher than the corresponding probability of those who are subject to the effect in model (A) (or (B)). The marginal effects of the absence of the sign effect on the debtors' debt amounts are JPY 0.26 million for model (A) and JPY 0.27 million for model (B). Borrowing aversion associated with the sign effect is so strong that all of the estimated marginal effects of the absence of the sign effect are larger than the marginal effects of one-standard-deviation increase both in $\alpha$ and $\rho$.

\subsubsection{Debt purposes}

We also estimate the probability functions of debt holding for various purposes. The results are summarized in panel B of Table 4. As the proportion of borrowers for each specific purpose is small (at most $8 \%$ from Table 1), the estimation results are not so strong as those for overall debt. However, the sign conditions predicted from $\mathrm{H} 1$ through $\mathrm{H} 4$ are met in almost all cases. Although it seems difficult to find out strong tendency from the results, it might be noteworthy that declining impatience is significant for debts for cars and amusements whereas it is not for living costs and business. To be rough, the effect of present bias seems to occur more clearly for debt holding which is less closely related to subsistence.

\subsubsection{Inclination toward overborrowing}

We detect for the marginal effects of the three time-discounting variables $(\alpha, \rho, \theta)$ on the respondents' inclination toward overborrowing. To do so, we estimate probit models for the probabilities of: displaying a debt-to-income ratio being higher than 30\%; having credit-card debts; having the experience of borrowed unsecured consumer loans; having the experience of having been denied a loan; and the experience of having engaged in debt-restructuring or of declared personal bankruptcy.

Table 5 summarizes the results. Consistent with hypothesis H2, an increase in declining impatience $\alpha$ is shown to lead naïve respondents to have stronger inclination to overborrow. It is valid in almost all cases at high significance levels. For example, naïve respondents whose $\alpha$ is higher by one unit of standard deviation $(0.046)$ are $2.31(=4.6 * 0.503)$ percentage-points more likely to have credit-card debts. The marginal effect is more than one fourth of the prevalence rate of credit-card debtors ( $8.6 \%$ from Table 1$)$. 
In contrast, as expected by hypothesis $\mathrm{H} 3$, the sophisticated respondents does not show significant association between declining impatience and overborrowing inclination, except for the case of the default experience (debt restructuring or personal bankruptcy). Sophisticated respondents with a higher degree of declining impatience are less likely to have the default experience. The result is somewhat puzzling and might be hard to understand theoretically.

\section{Insert Table 5.}

For all cases, overborrowing inclination is highly correlated with impatience $\rho$. For model (A) (or (B)), an increase in $\rho$ by one standard deviation is associated with a 2.5 (or 2.4) percentage-point higher probability of exhibiting higher debt-to-income ratios than $30 \%$. The marginal effect is not that small when compared with the corresponding unconditional probability, $8.1 \%$ (see Table 1): the marginal effect relative to the unconditional probability amounts to $30.9 \%$. The marginal effect on the probability of having credit-card debts is 2.2 percentage points for model (A) and 1.9 percentage points for (B), which are around one fourth of the unconditional probability (8.6\%). The marginal effects on the probability of having ever borrowed unsecured consumer loans are around $1 \%$.

As for the sign effect, expected negative association is observed for the probability of exhibiting higher debt-to-income ratios than $30 \%$ : the incidence of the sign effect is associated with a 3.2 percentage-point decrease in the probability, which is greater in magnitude than the marginal effect of one-standard-deviation increase both in $\alpha$ and $\rho$. However, association with the other overborrowing variables are not detected.

\section{Discussions}

For robustness check, we re-examine the above analysis in two ways. Firstly, we re-conduct regression using as a regressor a binary indicator for the present-biased respondent $(\alpha>0)$, instead of declining impatience $\alpha$. This enables us to focus on the effect of having present-biased preferences under a weaker condition. Secondly, to rule out the possibility that the above results simply reflect that responses 
indicative of declining and/or low impatience are a consequence of overborrowing rather than the cause of it, we conduct the same regression as in the previous section by excluding from the sample any respondent who could be taken as seriously credit-constrained.

\subsection{Regressions with the present-bias dummy}

In the previous section, we have estimated the generalized hyperbolic discount function, which enables us to detect the marginal effect of a parametric increase in the degree of declining impatience on borrowing behavior. However, the results may depend on the specification of the discount function. To focus on the effect of the incidence of present bias on borrowing behavior by giving up detecting the effect of differences in the degree of declining impatience $\alpha_{i}$, let us use for a regressor the binary indicator, instead of $\alpha_{i}$, which equals one if the respondent is present biased $\left(\alpha_{i}>0\right)$ and zero otherwise.

Table 6 summarizes the results, where in the column of "Present bias $(\alpha>0)=1$ " the marginal effects compared with the case without present bias are shown. The results are consistent with our hypotheses and the results of Table 4 in the previous section. In particular, naïve respondents are 4.7 percentage-points more likely to have debt, and have a JPY 0.11 million larger amounts of debt, than respondents without present bias, whereas there is no significant difference both in the probability of being indebted and the amounts of debt holding between sophisticates with present bias and respondents without present bias.

\section{Insert Table 6.}

The marginal effects on overborrowing inclination are summarized in Table 7. Except for that the marginal effects of the incidence of present bias on the probability of having the experiences of having borrowed unsecured consumer loans are insignificant, the results are consistent in that the naïve are more likely to overborrow.

\section{Insert Table 7.}


The result on credit-card debts is comparable with that of Meier and Sprenger (2010), which reports that the presence of present bias leads to a 16 percentage-point increase in the probability of having credit-card debts. In Table 7, the corresponding marginal effect of the presence of present bias amounts to 4.8 percentage points for naïve respondents and 3.1 percentage points for average respondents. Although the effects are much smaller than Meier and Sprenger's estimate, the relative magnitudes to the prevalence rate of credit-card debtors (i.e., the unconditional probability of having credit card debts), i.e., $38.4 \%$ $(=4.8 / 12.5)$ for naïve respondents and $36.0 \%(=3.1 / 8.6)$ for average respondents, are just as high as the corresponding ratio that is computed from Meier and Sprenger's estimate $(16 / 41=39.0 \%) .{ }^{16}$

\subsection{Excluding credit-constrained respondents}

It should be noted that the observed association between time discounting and debt holding could be interpreted as that overborrowing causes high and/or declining impatience: Credit-constrained respondents with excessive debt might be likely to choose smaller amounts of money with front-end delay to pay off outstanding debt and/or live on today, which may lead them to reveal high discount rates and cause positive association between debt and impatience. When the credit problem is very serious, the respondents might be much more impatient in immediate future choices than in distant future choices, which may lead them to reveal declining impatience and cause positive association between debt and declining impatience.

To consider this problem, recall first that in Questions Q1 and Q2, from which we estimate the degree of declining impatience, the smaller amount of money with front-end delay is set to JPY1,000 (around USD12.3). It might not be a plausible interpretation to take that intertemporal choices of such small money are strongly affected by their credit conditions unless the respondents face such a serious financial difficulty that they hardly live on the current week or month.

Given our data restriction, one possible way to check the robustness against the problem of our main results above is to reestimate equations by excluding credit-constrained respondents from the sample. To do it, we exclude from the sample any respondent with a credit problem or a troubled credit history who

\footnotetext{
${ }^{16}$ As seen by comparing the log pseudolikelihood values of Tables 4 and 6, the regression model with $\alpha_{i}$ fits better than the model with the present bias dummy, especially for the overall debt holding.
} 
has borrowed to pay off other debts; has the experiences of having denied a loan for whatever reason; or has the experiences of having engaged in debt restructuring or declared personal bankruptcy. The number of the respondents excluded amounts to 280 .

Table 8 shows the results. Our main results, the validity of hypotheses $\mathrm{H} 1$ through $\mathrm{H} 4$, are shown to be robust for overall debt behavior captured by the probability of being a debtor and by the amount of debt holding. Although the results for the overborrowing inclination become somewhat weaker, the coefficients of the degree of declining impatience are significant for the probability of exhibiting a debt-to-income ratio higher than $30 \%$ and that of having credit-card debts. It is also confirmed that less patient respondents are more likely to have credit-card debts. In this sample, however, the probability of having the experiences of having borrowed unsecured loans does not have significant correlation with any time discounting variables. $^{17}$

\section{Insert Table 8.}

\section{Conclusions}

We have shown that consumers' borrowing behavior have expected correlations with time discounting, including decision biases such as hyperbolic discounting and the sign effect. Although these time discounting variables have been often emphasized in theory as important determinants of indebtedness, empirical examination has not been conducted in a direct way. By identifying naïve and sophisticated respondents, our study has quantified substantial positive associations of (over-)indebtedness with hyperbolic discounting and impatience, and substantial negative correlations with the sign effect.

Three novelties are there. Firstly, respondents preferences are parameterized by using the generalized hyperbolic discount function, so that the elicited degree of declining impatience is used to detect

\footnotetext{
${ }^{17}$ We also estimated debt holding equations by excluding from the sample respondents whose debt/income ratios are greater than $30 \%$ as credit-constrained respondents. The results are again supportive of our results obtained in the previous section regarding overall debt holding as well as overborrowing inclination.
} 
association between the degree of present bias and debt holding behavior. Secondly, we try to distinguish naïve and sophisticated respondents by using self reporting data on the gap between plan and actual behavior over onerous assignments. Thirdly, borrowing aversion associated with the sign effect, i.e., the gain-loss asymmetry in time discounting, is also detected. 


\section{Appendix A: An illustrative model}

In this appendix, we illustrate theoretically relations between declining impatience and borrowing behavior of the naïve and the sophisticated using a simple three-period model. Consider a hyperbolic naïve consumer in the three period setting. Let $c_{\tau}$ and $u\left(c_{\tau}\right)$ denote period- $\tau$ consumption the period utility function, respectively. The gross rate of interest $\mathrm{R}$ is constant. In the initial period 1 , the naïve consumer determines his "optimal" consumption $\mathrm{c}_{1}$ from the intertemporal optimality conditions,

$$
\begin{gathered}
\frac{u^{\prime}\left(c_{1}\right)}{u^{\prime}\left(c_{1}\right)}(1+\alpha)^{\eta}=R \\
\frac{u^{\prime}\left(c_{2}\right)}{u^{\prime}\left(c_{3}\right)}\left(\frac{1+2 \alpha}{1+\alpha}\right)^{\eta}=R
\end{gathered}
$$

and the lifetime budget constraint,

$$
c_{1}+\frac{c_{2}}{R}+\frac{c_{3}}{R^{2}}=W_{1}
$$

where $W_{1}$ is initial wealth holding. As $1+\alpha>(1+2 \alpha) /(1+\alpha)$, the conditions imply that the consumer puts a greater weight on the immediate gratification from $c_{1}$ than he expects to put on the period-2 immediate gratification from $c_{2}$. Since this tendency is stronger with $\alpha$, a larger $\alpha$ results in larger debt holdings in the period.

In period 2, the naïve consumer re-determines $\left(c_{2}, c_{3}\right)$ from the the period-2 optimality condition,

$$
\frac{u^{\prime}\left(c_{2}\right)}{u^{\prime}\left(c_{3}\right)}(1+\alpha)^{\eta}=R
$$

which differs from the period-1 condition (4): gratification from $c_{2}$ is evaluated more highly than in (4). The realized $c_{2}$ is thus larger than the level which was planned in the previous period, whereas the opposite is true for $c_{3}$.

To be more specific, if $u\left(c_{\tau}\right)$ is specified by the power function,

$$
u(c)=\frac{c^{1-\gamma}-1}{1-\gamma}, \gamma>0,
$$

the naïve consumer's "optimal" consumption rates are given by 


$$
\begin{gathered}
c_{1}^{N}=\lambda_{11} W_{1}, \\
c_{2}^{N}=\lambda_{22} W_{2}^{N}, \\
c_{3}^{N}=\left(1-\lambda_{22}\right) R W_{2}^{N},
\end{gathered}
$$

where $W_{2}^{N}$ is wealth in period 2, $R\left(W_{1}-c_{1}^{N}\right)$; and $\lambda_{11}$ and $\lambda_{22}$ represent the realized marginal propensities to consume (MPC) in periods 1 and 2, respectively:

$$
\begin{aligned}
& \lambda_{11}=\frac{1}{1+R^{-1}\{R f(1)\}^{1 / \gamma}+R^{-2}\left\{R^{2} f(2)\right\}^{1 / \gamma}}, \\
& \lambda_{22}=\frac{1}{1+R^{-1}\{R f(1)\}^{1 / \gamma}} .
\end{aligned}
$$

From these solutions, as $f(\tau)^{\prime}$ s are decreasing in $\alpha$, a large $\alpha$ implies a large $c_{1}{ }^{N}$ and a small $c_{3}{ }^{N}{ }^{18}$ In this sense, naïve consumers with stronger declining impatience are likely to hold larger debts.

When the consumer is a sophisticate, who expects correctly the incidence of the preference reversal from (4) to (5), he first solves (5) for $\left(c_{2}, c_{3}\right)$ by taking $c_{1}$ and hence period-2 wealth $\mathrm{W}_{2}$ as given. Once the optimal $c_{2}$ and $c_{3}$ are obtained as functions of $\mathrm{c}_{1}$, by substituting functions $c_{2}\left(c_{1}\right)$ and $c_{3}\left(c_{1}\right)$ into the lifetime utility maximization problem, the consumer determines the optimal $c_{1}$ and hence $c_{2}$ and $c_{3}$.

In the illustrative model, the sophisticate's optimal consumption $c_{t}^{S}$ in period $\mathrm{t}$ is obtained as

$$
\begin{aligned}
& c_{1}^{S}=\lambda_{11}^{\prime} W_{1}, \\
& c_{2}^{S}=\lambda_{22} W_{2}^{S}, \\
& c_{3}^{S}=\left(1-\lambda_{22}\right) R W_{2}^{S},
\end{aligned}
$$

where $W_{2}^{S}=R\left(W_{1}-c_{1}^{S}\right)$; and the MPC $\lambda_{11}^{\prime}$ in period 1 is defined in the same way as in (9) by using effective discount factors $f^{S}(\tau)(\tau=1,2)$, instead of $f(\tau)$ :

$$
\begin{aligned}
& f^{s}(1)=\lambda_{22}^{\prime} f(1)+\left(1-\lambda_{22}\right) f(2) / f(1), \\
& f^{s}(2)=f(1) f^{s}(1)
\end{aligned}
$$

The solution differs from the naïve consumer's solution only in the MPC in period 1: it is defined by

\footnotetext{
${ }_{18}$ The effect of an increase in $\alpha$ on $c_{2}$ are ambiguous because it raises the marginal propensity to consume from $W_{2}$ whereas it reduces $W_{2}$ by raising $c_{1}$.
} 
using the effective discount factors $f^{S}(\tau)$, instead of $f(\tau)$. The effective discount factor $f^{S}(1)$ for period 2 is a weighted average of the corresponding original discount factor $f(1)$ and the original future one-period discount factor for period 3 computed as $f(2) / f(1)$. Since, as is easily seen, $f^{S}(1)>f(1)$ and $f^{S}(2)>f(2)$, which means that the sophisticate behaves as if he had a lower discount rate when comparing felicities from $c_{1}$ and $c_{2}$ and a higher discount rate when comparing felicities from $c_{2}$ and $c_{3}$ than he would if he were naïve. Due to these opposite effects, it is theoretically ambiguous whether the sophisticated consumer's MPC in period $1\left(\lambda_{11}^{\prime}\right)$ is smaller than the naïve one's $\left(\lambda_{11}\right){ }^{19}$

Nevertheless, it may be natural to hypothesize that the sophisticated consumer would weaken somehow overconsumption/undersaving and overborrowing because period-1 self has an incentive to use some devices to commit to his lifetime consumption plan. In fact, when there is an commitment device, the period-1 self commits to his lifetime consumption plan which is obtained from (3) and (4) (not (5)), so that the sophisticate's solution can be shown to satisfy:

$$
c_{1}^{S}=c_{1}^{N}, c_{2}^{S}<c_{2}^{N} \text {, and } c_{3}^{S}>c_{3}^{N} \text {, with commitment devices }
$$

meaning that the sophisticate restrains $c_{2}{ }^{S}$, and mitigates undersaving and/or overborrowing. ${ }^{20}$

19 As shown in the literature (e.g., Phelps and Pollack, 1968; Laibson, 1996; and O'Donoghue and Rabin, 1999), the solution of the naive and that of the sophisticated coincide when the relative risk aversion $\gamma$ equals one, i.e., when the felicity function is logarithmic. We can verify that our solutions satisfy the same property.

${ }^{20}$ From (3), (4), and the lifetime budget, the solution with commitments are obtained as $c_{2}{ }^{S}=\lambda_{21} R W_{1}$ and $c_{3}^{S}=\left(1-\lambda_{11}-\lambda_{21}\right) R^{2} W_{1}$, where $\lambda_{11}$ is given by (9); and

$$
\lambda_{21}=\frac{R^{-1}\{R f(1)\}^{1 / \gamma}}{1+R^{-1}\{R f(1)\}^{1 / \gamma}+R^{-2}\left\{R^{2} f(2)\right\}^{1 / \gamma}} .
$$

From this and (8), it can be shown that, with commitment devices, $c_{3}{ }^{S}-c_{3}{ }^{N} \propto f(2)^{1 / \gamma}-f(1)^{2 / \gamma}>0$. 
Appendix B: Questions in Q1 and Q2

Insert Figure A1. 


\section{Appendix C: Q6 and its payoff table}

Q6. Suppose you have two options to pay some money. You may choose Option "A", to pay JPY 1 million today; or Option "B", to pay a different amount in a year. Compare the amounts and timing in Option "A" with Option "B" and indicate which amount you would prefer to pay for each of all 9 choices.

$\begin{array}{cccc}\text { Option A - paying today } & \text { A } & \text { B } & \text { Option B - paying in a year } \\ \text { JPY1,000,000 (USD12,330) } & \square & \square & \text { JPY 920,000 (USD11,344) } \\ \text { JPY1,000,000 (USD12,330) } & \square & \square & \text { JPY 970,000 (USD11,961) } \\ \text { JPY1,000,000 (USD12,330) } & \square & \square & \text { JPY1,000,000 (USD12,330) } \\ \text { JPY1,000,000 (USD12,330) } & \square & \square & \text { JPY1,001,000 (USD12,343) } \\ \text { JPY1,000,000 (USD12,330) } & \square & \square & \text { JPY1,005,000 (USD12,392) } \\ \text { JPY1,000,000 (USD12,330) } & \square & \square & \text { JPY1,010,000 (USD12,454) } \\ \text { JPY1,000,000 (USD12,330) } & \square & \square & \text { JPY1,050,000 (USD12,947) } \\ \text { JPY1,000,000 (USD12,330) } & \square & \square & \text { JPY1,100,000 (USD13,564) } \\ \text { JPY1,000,000 (USD12,330) } & \square & \square & \text { JPY1,300,000 (USD16,029) }\end{array}$


Angeletos, G-M, D. Laibson, A. Reppeto, J. Tobacman, S. Weinberg, 2001, The hyperbolic consumption model: Calibration, simulation, and empirical evaluation, Journal of Economic Perspective 15, 47-68.

Anderson, S., G.W. Harrison, M.I. Lau, and E.E. Rutsrom, 2008, Eliciting risk and time preferences, Econometrica 76, 583-618.

Ainslie, G., 2001, Breakdown of Will, Cambridge, UK: Cambridge University Press.

Charbris, C.F., D. Laibson, C.L. Morris, J.P. Shuldt, and D. Taubinsky, 2008, Individual laboratory-measured discount rates predict field behavior, Journal of Risk and Uncertainty 37, 237-269.

Eisenhauer, J.G. and L. Ventura, 2006, The prevalence of hyperbolic discounting: Some European evidence, Applied Economics 38, 1223-1234.

Fisher, I., 1930, The Theory of Interest, New York, U.S.A.: The Macmillan Co.

Frederick, S.G., G. Loewenstein, and T. O'Donoghue, 2002, Time discounting and time preference: A critical review, Journal of Economic Literature 40, 351-401.

Harrison, G.W., M.I. Lau, and M.B. Williams, 2002, Estimating individual discount rates in Denmark: A field experiment, American Economic Review 92, 1606-1617.

Heidhue, P. and B. Köszegi, 2010, Exploiting naïvete about self-control in the credit market, American Economic Review 100, 2279-2303.

Hey, J.D. and G. Lotito, 2009, Naïve, resolute or sophisticated? A study of dynamic decision making, Journal of Risk and Uncertainty 38, 1-25.

Hiruma, F. and S. Ikeda, 2007, A study on time discounting based on experiments and an inquiry survey, Review of Monetary and Financial Studies 25, 14-33 (in Japanese).

Ikeda, S., M. Kang, and F. Ohtake, 2010, Hyperbolic discounting, the sign effect, and the body mass index, Journal of Health Economics 29, 268-284.

Ikeda, S., M. Kang, F. Ohtake, and Y. Tsutsui, 2010, Time preference, time discounting biases, and debt holding behaviors, mimeo.

Kang, Myong-Il and S. Ikeda, 2011, Time discouting and smoking behavior under tax hike, mimeo.

Karlan, D. and Zinman J, 2008, Lying about borrowing, Journal of the European Economic Association 6, $510-521$.

Krusell, P., B. Kuruşçu, and A. A. Smith, Jr., 2002, Equilibrium welfare and government policy with 
quasi-geometric discounting, Journal of Economic Theory 105, 42-72.

Khwaja, A., D. Silverman, and F. Sloan, 2007, Time preference, time discounting, and smoking decisions, Journal of Health Economics 26, 927-949.

Laibson, D., 1996, Hyperbolic discount function, undersaving, and saving policy, NBER Working Paper 5635.

Laibson, D., 1997, Golden eggs and hyperbolic discounting, Quarterly Journal of Economics, 112, 443-477.

Laibson, D., A. Reppeto, and J. Tobacman, 2003, A debt puzzle, in: P. Aghion, R. Frydman, and J. Stiglitz, M. Woodford, eds., Knowledge, Information, and Expectations in Modern Economics: In Honor of Edmund S. Phelps, Princeton: Princeton University Press, Chap.11, 228-266.

Laibson, D., A. Reppeto, and J. Tobacman, 2007, Estimating discount functions with consumption choices over lifecycle, NBER Working Paper Series 13314, forthcoming in American Economic Review.

Loewenstein, G., and D. Prelec, 1992, Anomalies intertemporal choice: Evidence and an interpretation, Quarterly Journal of Economics, 107, 573-597.

Meier, S. and C. Sprenger, 2010, Present-biased preferences and credit card borrowing, American Economic Journal: Applied Economics 2:1, 193-210.

O'Donoghue, T. and M. Rabin, 1999, Doing it or later, American Economic Review 89, 103-125.

Ottaviani, C. and D. Vandone, 2011, Impulsivity and household indebtedness: Evidence from real life, Journal of Economic Psychology 32, 754-761.

Phelps, E.S. and R.A. Pollack, 1968, On second-best natural savings and game-equilibrium growth, Review of Economic Studies 35, 185-199.

Skiba, P.M., and J. Tobacman, 2008, Payday loans, uncertainty, and discounting: Explaining patterns of borrowing, repayment, and default, mimeo.

Sourdin, P., 2008, Pension contributions as a commitment device: Evidence of sophistication among time-consistent households, Journal of Economic Psychology 29, 577-596.

Tanaka, T. and T. Murooka, 2010, Self control problems and consumption-saving decisions: Theory and empirical evidence, mime.

Tsutsui, Y., F. Hiruma, F. Ohtake, and S. Ikeda, 2007, On the usury caps: The behavioral economic 
approach, Modern Finance, 25-73 (in Japanese).

Wong, W-K., 2008, How much time-inconsistency is there and does it matter? Evidence on self-awareness, size, and effects, Journal of Economic Behavior \& Organization 68, 645-656. 
Table 1

Summary statistics

\begin{tabular}{|c|c|}
\hline Panel A. Background attributes & ${ }_{N}^{\text {Mean }}{ }^{\text {(S.D.) }}$ \\
\hline Age & $\begin{array}{c}41.763(12.46) \\
2386\end{array}$ \\
\hline Male & $\begin{array}{c}0.499 \quad(0.50) \\
2386\end{array}$ \\
\hline University grad. & $\begin{array}{c}0.546 \quad(0.50) \\
2386\end{array}$ \\
\hline Household income (in JPY million) & $\begin{array}{c}6.90 \quad(4.09) \\
2361\end{array}$ \\
\hline Household's financial assets (in JPY million) & $\begin{array}{c}14.53 \quad(23.67) \\
2345\end{array}$ \\
\hline Household's real assets (in JPY million) & $\begin{array}{c}21.15 \quad(29.54) \\
2351 \\
\end{array}$ \\
\hline Panel B. Debt-related attributes & \\
\hline Debtors & $\begin{array}{c}0.202 \quad(0.40) \\
2386\end{array}$ \\
\hline Debt amounts (in JPY million) & $\begin{array}{c}0.50 \quad(0.17) \\
2386\end{array}$ \\
\hline Debt amounts when debtor=1 (in JPY million) & $2.45483^{(0.32)}$ \\
\hline Debt for: & $\begin{array}{c}0.066 \quad(0.25) \\
2386\end{array}$ \\
\hline Other goods & $\begin{array}{c}0.080 \quad(0.27) \\
2386\end{array}$ \\
\hline Living costs & $\begin{array}{c}0.041 \quad(0.20) \\
2386\end{array}$ \\
\hline business & $\begin{array}{c}0.017 \quad(0.13) \\
2386\end{array}$ \\
\hline Amusements & $\begin{array}{c}0.016 \quad(0.13) \\
2386\end{array}$ \\
\hline Paying off other debt & $\begin{array}{c}0.020 \quad(0.14) \\
2386\end{array}$ \\
\hline Debt-to-income ratio $>0.3$ & $\begin{array}{c}0.081 \quad(0.27) \\
2386\end{array}$ \\
\hline Having credit-card debts & $\begin{array}{c}0.086 \quad(0.28) \\
2364\end{array}$ \\
\hline $\begin{array}{l}\text { Having experiences of having borrowed } \\
\text { unsecured consumer loans }\end{array}$ & $\begin{array}{c}0.087 \quad(0.28) \\
2386\end{array}$ \\
\hline $\begin{array}{l}\text { Having experiences of having been denied a } \\
\text { loan for whatever reason }\end{array}$ & $\begin{array}{c}0.118 \quad(0.32) \\
2386\end{array}$ \\
\hline $\begin{array}{l}\text { Having experiences of having engaged in debt } \\
\text { restructuring or declared personal bankruptcy }\end{array}$ & $\begin{array}{c}0.021(0.14) \\
2378 \\
\end{array}$ \\
\hline
\end{tabular}

Note : Data source: The original internet survey, The Japan Internet Survey on Preferences Relating To Time and Risk 2010 (JPTR 2010). Mortgage loans are excluded fron debt. 
Table 2.

Generalized hyperbolic discounting, the sign effect, and impatience.

\section{Panel A. Generalized hyperbolic discount function}

$\begin{array}{ll}\text { Declining impatience } & \alpha \\ & \text { Declining impatience }(\alpha>0) ? \\ \text { Intercept } & \alpha^{*} \eta \\ \text { Discount rates } & \rho(7)((1)) \\ & \rho(372)((2))\end{array}$

Panel B. Implied discount rates from Q5 and Q6

$\begin{array}{ll}\text { Discount rates for: } & \text { receipts Q5 }((3)) \\ & \text { payments Q6 }((4)) \\ \text { The sign effect }((3)>(4)) ? & \end{array}$

$\begin{array}{cc}0.018 & (0.001) \\ \text { Yes } \\ 0.050(0.001) \\ 0.039(0.001) \\ 0.029(0.001)\end{array}$

$0.025(0.003)$
Yes
$0.065(0.004)$

$0.016(0.001)$

$$
\text { Yes }
$$

$0.049(0.002)$

$0.046(0.002)$

$0.037(0.001)$

$0.032(0.003) \quad 0.028(0.001)$

$0.028(0.001)$

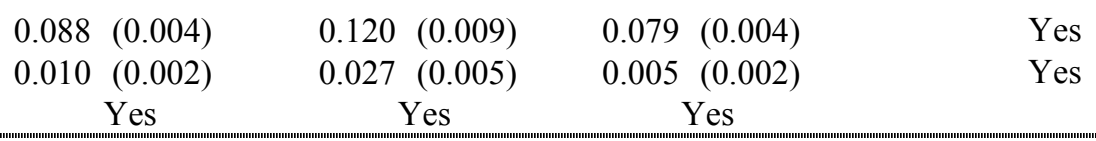

Panel C. The degree of impatience

Impatience $\rho$ (standardized average of (1)-(4))

$-0.007(0.014)$

$0.159(0.034)$

$-0.048(0.015)$

Yes

Note: Standard errors in paretheses. See equations (1) and (2) for the meanings of parameters $\alpha, \eta$, and $\rho . *$ All the 'Yes's represent that the differences are significent with P-values smaller than 0.000.**'Insignificant' represents that the corresponding P-value equals 0.15 . 
Table 3

Summary statistics stratified by time discounting variables.

\begin{tabular}{|c|c|c|c|}
\hline \multicolumn{4}{|c|}{$\begin{array}{l}\text { Declining impatience }(\alpha) \\
\end{array}$} \\
\hline & & $\alpha \leqq 0$ & $\chi^{2}$ test \\
\hline \begin{tabular}{c}
\multicolumn{2}{c}{ Naif } \\
Mean (S.D.)
\end{tabular} & $\begin{array}{l}\text { Sophisticate } \\
\text { Mean (S.D.) }\end{array}$ & Mean (S.D.) & $\chi^{2}$ statistics \\
\hline $\mathrm{N}$ & $\mathrm{N}$ & $\mathrm{N}$ & $\begin{array}{l}\text { (P-value) } \\
\text { (P) }\end{array}$ \\
\hline
\end{tabular}

\begin{tabular}{|c|c|c|}
\hline \multicolumn{3}{|c|}{ Impatience $(\rho)$} \\
\hline$\rho>$ mean & $\rho \leqq$ mean & $\chi^{2}$ test \\
\hline Mean ${ }_{\mathrm{N}}^{\text {(S.D.) }}$ & $\begin{array}{l}\text { Mean (S.D.) } \\
\mathrm{N}_{\mathrm{N}}\end{array}$ & $\begin{array}{l}\chi^{2} \text { statistics } \\
\text { (P-value) }\end{array}$ \\
\hline
\end{tabular}

\begin{tabular}{ccc}
\hline \hline \multicolumn{3}{c}{ Sign effects ( $\theta)$} \\
\hline$\theta=1$ & $\theta=0$ & $\chi^{2}$ test \\
\hline Mean (S.D.) & Mean ${ }^{\text {(S.D.) }}$ & $\chi^{2}$ statistics \\
$\mathrm{N}$ & $\mathrm{N}$ & (P-value) \\
\hline
\end{tabular}

Age

Male

University grad.

Household income (in JPY million)

Household's financial assets (in JPY million)

Household's real assets (in JPY million)

Panel B. Debt-related attributes

Debtors

Debt amounts (in JPY million)

Debt amounts when debtor=1 (in JPY million)

Debt for:

\begin{tabular}{|c|c|c|c|}
\hline (12.44) & (12.65) & 39.26 (11.87) & 198.84 \\
\hline 576 & 384 & 1317 & $(0.00)$ \\
\hline $0.516 \quad(0.50)$ & $0.521 \quad(0.50)$ & $0.472 \quad(0.50)$ & 4.61 \\
\hline 576 & 384 & 1317 & $(0.10)$ \\
\hline $0.523 \quad(0.50)$ & $0.531 \quad(0.50)$ & $0.541 \quad(0.50)$ & 1.10 \\
\hline 576 & 384 & 1317 & $(0$. \\
\hline $7.00 \quad(4.32)$ & $7.26 \quad(4.11)$ & $6.75 \quad(3.97)$ & 29.59 \\
\hline 565 & 381 & 1307 & $(0.13)$ \\
\hline $3.08 \quad(22.17)$ & $16.22(23.03)$ & $14.86(24.62)$ & 29.64 \\
\hline 560 & 380 & 1298 & $(0.04)$ \\
\hline $2.46 \quad(28.98)$ & $24.93(31.57)$ & $19.52 \quad(29.31)$ & 36.13 \\
\hline & 382 & 1299 & $(0.01)$ \\
\hline
\end{tabular}

$45.15 \quad(12.32) \quad 40.32 \quad(12.19) \quad 116.69$ $\begin{array}{cccc}703 & 1588 & (0.00) \\ 0.578 \quad(0.49) & 0.463 \quad(0.50) & 25.67\end{array}$ $\begin{array}{cccc}0.578 \quad(0.49) & 0.463(0.50) & 25.67 \\ 703 & 1588 & (0.00)\end{array}$ $\begin{array}{lllll}0.498 & (0.50) & 0.55 & (0.50) & 6.08\end{array}$ $\begin{array}{cccc}703 & 1588 & (0.01) \\ 6.71 & (4.15) & 7.00 \quad(4.07) & 17.44\end{array}$ $\begin{array}{cccc}6.71(4.15) & 7.00 \quad(4.07) & 17.44 \\ 693 & 1574 & (0.10)\end{array}$ $\begin{array}{lllll}3.96 & (24.69) & 15.01 & (23.43) & 31.81\end{array}$ $\begin{array}{lll}687 & 1564 & (0.00)\end{array}$ \begin{tabular}{rrrr}
$21.35 \quad(30.55)$ & $21.48 \quad(29.59)$ & 12.43 \\
692 & 1566 & $(0.19)$ \\
\hline
\end{tabular}

$\begin{array}{lllllll}0.238 & (0.43) & 0.203 & (0.40) & 0.181 & (0.38) & 8.25\end{array}$

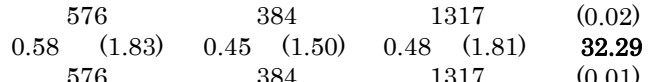
$\begin{array}{cccccc}2.45 \quad(3.08) & 2.21 & (2.68) & 2.63 & (3.55) & 23.24 \\ 137 & & 78 & 238 & (0.06)\end{array}$

\begin{tabular}{|c|c|c|c|c|}
\hline Cars & $\begin{array}{c}0.064 \underset{576}{(0.25)} \\
576\end{array}$ & $\begin{array}{c}0.076 \quad(0.26) \\
384\end{array}$ & $\begin{array}{c}0.059 \quad(0.24) \\
1317\end{array}$ & $\begin{array}{r}1.35 \\
(0.51)\end{array}$ \\
\hline Other goods & $\begin{array}{c}0.106 \quad(0.31) \\
576\end{array}$ & $\begin{array}{c}0.073 \quad(0.26) \\
384\end{array}$ & $\begin{array}{c}0.071 \quad(0.26) \\
1317\end{array}$ & $\begin{array}{r}6.81 \\
(0.03)\end{array}$ \\
\hline Living costs & $\begin{array}{cc}0.071 \quad(0.26) \\
576\end{array}$ & $\begin{array}{c}0.029(0.17) \\
384\end{array}$ & $\begin{array}{c}0.032 \quad(0.18) \\
1317\end{array}$ & $\begin{array}{l}17.49 \\
(0.00)\end{array}$ \\
\hline business & $\begin{array}{c}0.019 \quad(0.14) \\
576\end{array}$ & $\begin{array}{c}0.018 \quad(0.13) \\
384\end{array}$ & $\begin{array}{c}0.014 \quad(0.12) \\
1317\end{array}$ & $\begin{array}{c}0.9 \\
(0.6\end{array}$ \\
\hline Amusements & $\begin{array}{cc}0.031 & (0.17) \\
576\end{array}$ & $\begin{array}{cc}0.01 & (0.10) \\
384\end{array}$ & $\begin{array}{c}0.01 \quad(0.10) \\
1317\end{array}$ & $\begin{array}{l}12.85 \\
(0.00)\end{array}$ \\
\hline an repayment & $\begin{array}{c}0.023 \quad(0.15) \\
576\end{array}$ & $\begin{array}{c}0.01 \quad(0.10) \\
384\end{array}$ & $\begin{array}{c}0.021 \quad(0.14) \\
1317\end{array}$ & $\begin{array}{r}2.12 \\
(0.35)\end{array}$ \\
\hline & $\begin{array}{c}0.104 \quad(0.31) \\
576\end{array}$ & $\begin{array}{c}0.089 \quad(0.28) \\
384\end{array}$ & $\begin{array}{c}0.068 \quad(0.25) \\
1317\end{array}$ & $\begin{array}{c}7.30 \\
(0.03)\end{array}$ \\
\hline & $\begin{array}{cc}0.125 \quad(0.33) \\
566\end{array}$ & $\begin{array}{c}0.073 \quad(0.26) \\
381\end{array}$ & $\begin{array}{c}0.07 \quad(0.26) \\
1308\end{array}$ & $\begin{array}{l}16.22 \\
(0.00)\end{array}$ \\
\hline & $\begin{array}{c}0.109 \quad(0.31) \\
576\end{array}$ & $\begin{array}{c}0.081 \quad(0.27) \\
384\end{array}$ & $\begin{array}{c}0.072 \quad(0.26) \\
1317\end{array}$ & $\begin{array}{c}5.01 \\
(0.08)\end{array}$ \\
\hline lenied a loa & $\begin{array}{c}0.163 \quad(0.37) \\
576\end{array}$ & $\begin{array}{c}0.104 \quad(0.31) \\
384\end{array}$ & $\begin{array}{c}0.101 \quad(0.30) \\
1317\end{array}$ & $\begin{array}{l}15.75 \\
(0.00)\end{array}$ \\
\hline & $0.033 \quad(0.18)$ & $0.01 \quad(0.10)$ & $0.019 \quad(0.14)$ & 6.33 \\
\hline
\end{tabular}
Having experiences of having been denied a loa for whatever reason

Having experiences of having engaged in deb restructuring or declared personal bankruptcy

\begin{tabular}{lll}
692 & 1566 & $(0.19)$ \\
\hline
\end{tabular}

$\begin{array}{lllll}0.277 & (0.45) & 0.162 & (0.37) & 39.76\end{array}$ \begin{tabular}{llll} 
& \multicolumn{2}{c}{153} & \multicolumn{2}{c}{1588} & $(0.00)$ \\
0.73 & $(2.08)$ & $0.37 \quad(1.50)$ & 45.63
\end{tabular} $\begin{array}{ccc}703 & 1588 & (0.00)\end{array}$

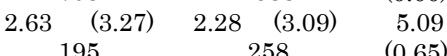

$\begin{array}{lllll}0.087 & (0.28) & 0.054 & (0.23) & 8.79\end{array}$ \begin{tabular}{cccc}
703 & \multicolumn{1}{c}{1588} & $(0.00)$ \\
$0.117 \quad(0.32)$ & $0.062 \quad(0.24)$ & 20.58
\end{tabular} $\begin{array}{lll}703 & 1588 & (0.00)\end{array}$ $\begin{array}{lllll}0.064 & (0.24) & 0.025 & (0.16) & 20.75\end{array}$ $\begin{array}{cccc}703 & 1588 & (0.00) \\ 0.033 \quad(0.18) & 0.01 \quad(0.10) & 15.04\end{array}$ $\begin{array}{lll}703 & 1588 & (0.00)\end{array}$ $\begin{array}{lllll}0.027 & (0.16) & 0.011 & (0.10) & 8.47\end{array}$ $\begin{array}{ccc}703 & 1588 & (0.00) \\ 0.027 & (0.16) & 0.016\end{array}$

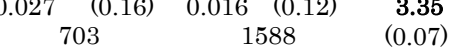
$\begin{array}{lllll}0.117 & (0.32) & 0.062 & (0.24) & 20.58\end{array}$ $\begin{array}{lll}703 & 1588 & (0.00)\end{array}$ $\begin{array}{lllll}0.125 & (0.33) & 0.064 & (0.24) & 24.12 \\ & & & 1576 & (0.00)\end{array}$ $0.127 \quad(0.33) \quad 0.065 \quad(0.25) \quad 18.96$ \begin{tabular}{ccccc} 
& 703 & \multicolumn{2}{c}{1588} & $(0.00)$ \\
0.165 & $(0.37)$ & 0.09 & $(0.29)$ & 27.69
\end{tabular} \begin{tabular}{lllll}
$0.038 \quad(0.19)$ & 0.013 & $(0.11)$ & 16.25 \\
\hline
\end{tabular}

$41.82 \quad(12.51) \quad 41.72 \quad(12.09) \quad 39.47$ \begin{tabular}{cccc}
1859 & \multicolumn{2}{c}{432} & $(0.70)$ \\
$0.501 \quad(0.50)$ & 0.486 & $(0.50)$ & 0.3
\end{tabular} $\begin{array}{cccc}0.501(0.50) & 0.486 & (0.50) & 0.3 \\ 1859 & 432 & (0.58)\end{array}$ $\begin{array}{lllll}0.528 & (0.50) & 0.56 & (0.50) & 1.63\end{array}$ $\begin{array}{lll}1859 & 432 & (0.20)\end{array}$ \begin{tabular}{cccc}
$6.91 \quad(4.09)$ & 6.94 & $(4.15)$ & 4.13 \\
1838 & \multicolumn{2}{c}{429} & $(0.97)$
\end{tabular} $\begin{array}{llll}14.31(23.26) & 16.32(26.07) & 10.80\end{array}$ $\begin{array}{lll}1825 & 426 & (0.29)\end{array}$ \begin{tabular}{ccc}
$21.01(29.29)$ & $23.28(32.24)$ & 8.11 \\
1832 & 426 & $(0.52)$ \\
\hline
\end{tabular}

$\begin{array}{lllll}0.189 & (0.39) & 0.234 & (0.42) & 4.37\end{array}$ $\begin{array}{ccc}1859 & 432 & (0.04) \\ 0.43 \quad(1.59) & 0.69 \quad(2.13) & 18.7\end{array}$ $\begin{array}{lll}1859 & 432 & (0.02)\end{array}$ $\begin{array}{lllll}2.28 \quad(3.03) & 2.96 & (3.58) & 12.66 \\ & & & & 101\end{array}$

$\begin{array}{lllll}0.056 & (0.23) & 0.1 & (0.30) & 11.09\end{array}$ $\begin{array}{ccc}1859 & 432 & (0.00)\end{array}$

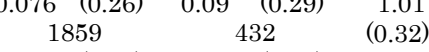
$\begin{array}{lllll}0.034 & (0.18) & 0.051 & (0.22) & 2.85\end{array}$ $\begin{array}{lll}1859 & 432 & (0.09)\end{array}$ $\begin{array}{lllll}0.017 & (0.13) & 0.019 & (0.13) & 0.07\end{array}$ $\begin{array}{ccc}1859 & 432 & (0.79)\end{array}$ $\begin{array}{ccccc}0.016 & (0.12) & 0.016 & (0.13) & 0.01 \\ 1859 & & 432 & (0.93)\end{array}$ $\begin{array}{lllll}0.018 & (0.13) & 0.025 & (0.16) & 1.11\end{array}$ $\begin{array}{ccc}1859 & 432 & (0.29) \\ 0.073(0.26) & 0.104(0.31) & 4.81\end{array}$ $\begin{array}{lllll}0.073 & (0.26) & 0.104 & (0.31) & 4.81\end{array}$ $\begin{array}{lll}1859 & 432 & (0.03)\end{array}$

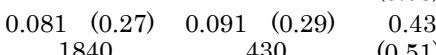
$0.085 \quad(0.28) \quad 0.081 \quad(0.27) \quad(0.12)$ $\begin{array}{ccc}0.085 & (0.28) & 0.081 \\ 1859 & 432 & (0.73)\end{array}$ \begin{tabular}{cccc}
1859 & \multicolumn{2}{c}{4} & 432 \\
$0.114 \quad(0.32)$ & $0.111 \quad(0.31)$ & 0.02 \\
1859 & & 432 & $(0.89)$
\end{tabular} $0.0192(0.14) \quad 0.10$

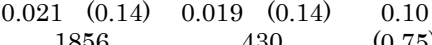

Note: Mortgage loans are excluded from debt. Bold digits for $\chi^{2}$ statistics represent the significance at the $10 \%$ level. 
Table 4

The marginal effects of time discounting on debt holding behavior.

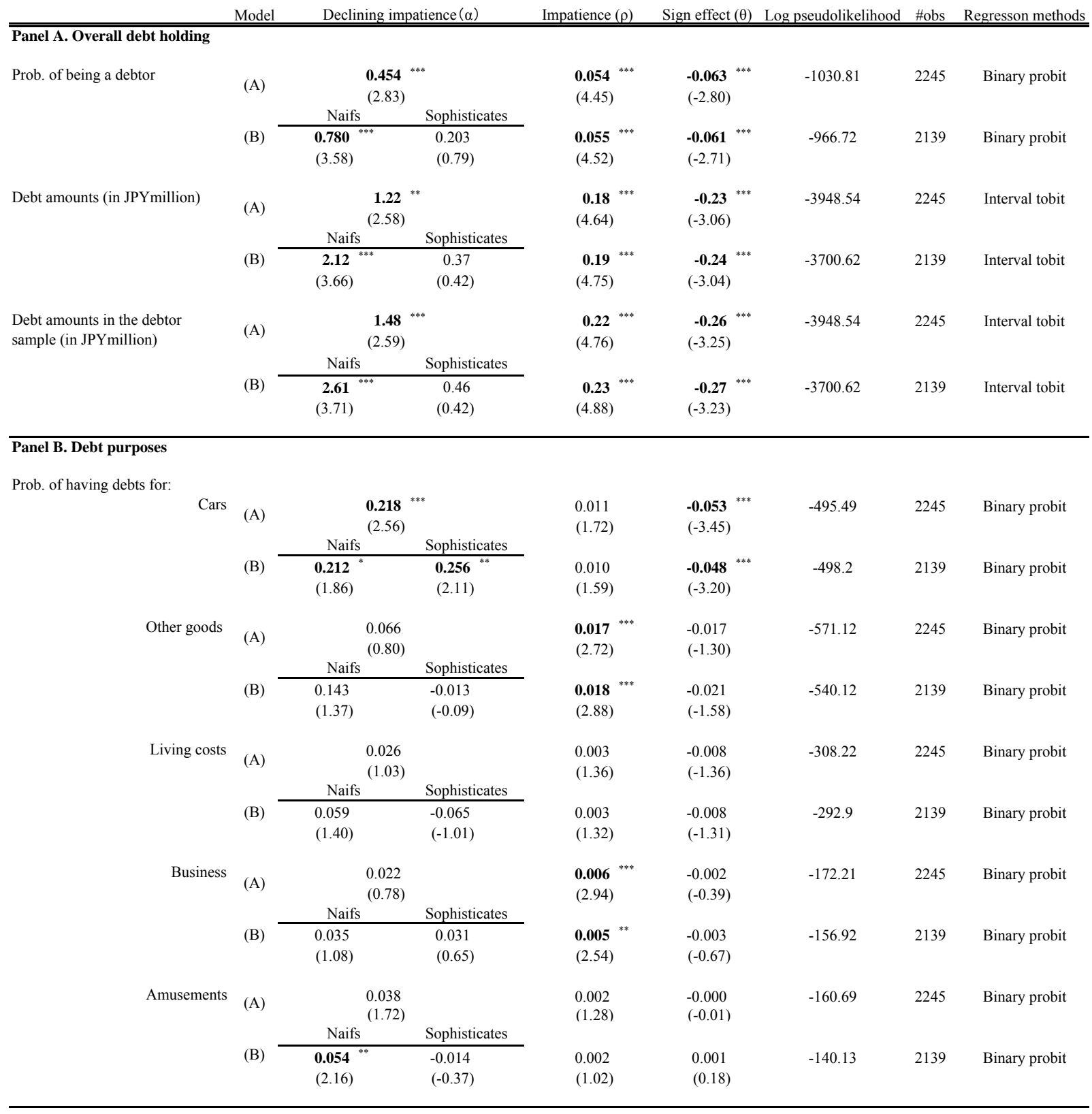

Note: The estimated marginal effects are listed with $\mathrm{z}$ values in parentheses. Control variables include: the degree of risk aversion, age, gender, education, household income, household real asset holding, household financial asset holding. *, **, *** represent statistical significance at the $10 \%, 5 \%$, and $1 \%$ levels, respectively. 
Table 5

The marginal effects of time discounting on overborrowing inclination.

Probability of: $\quad$ Model Declining impatience $(\alpha)$

Impatience $(\rho) \quad$ Sign effect $(\theta)$ Log pseudolikelihood \#obs Regresson methods

Debt-to-income ratio $>30 \%$

(A)

(B)

\begin{tabular}{cc} 
& $\begin{array}{c}0.142 \\
(1.49)\end{array}$ \\
Naifs & Sophisticates \\
\hline $\mathbf{0 . 3 0 9}^{* *}$ & 0.009 \\
$(2.56)$ & $(0.05)$
\end{tabular}

Having credit-card debts

(A)

$0.278^{* * *}$

(B)

\begin{tabular}{cl} 
Naifs $^{(2.77)}$ & Sophisticates \\
\hline $\mathbf{0 . 5 0 3}$ & -0.151 \\
$(4.07)$ & $(-0.85)$
\end{tabular}

Having experiences of

having borrowed unsecured

consumer loans

(A)

(B)

\begin{tabular}{cl}
\multicolumn{2}{c}{$\mathbf{0 . 0 9 8}^{*}$} \\
Naifs $^{(1.83)}$ & Sophisticates \\
\hline $\mathbf{0 . 1 7 9}{ }^{* * *}$ & -0.024 \\
$(2.65)$ & $(-0.27)$
\end{tabular}

Having experiences of

having been denied a loan

for whatever reason

Having experiences of

having engaged in debt

restructuring or declared

personal bankruptcy
0.236 **

(B)

\begin{tabular}{cc} 
Naifs & Sophisticates \\
\hline $\mathbf{0 . 4 5 8}^{* * *}$ & -0.111
\end{tabular}

(3.12) $\quad(-0.52)$

(A)

(B)

\begin{tabular}{cc}
\multicolumn{2}{c}{$\begin{array}{c}-0.035 \\
(1.06)\end{array}$} \\
Naifs & Sophisticates \\
\hline-0.010 & $\mathbf{- 0 . 2 4 7}^{*}$
\end{tabular}

$(-2.16)$

$0.024^{* * *} \quad-0.033^{* *}$

(3.40) (-2.19)

$\mathbf{0 . 0 2 2}^{* * *} \quad-0.016$

(3.02) (-1.08)

$\mathbf{0 . 0 1 9}{ }^{* * *} \quad-0.014$

(2.61) $\quad(-0.92)$

$\mathbf{0 . 0 1 0}^{* * *} \quad-0.001$

(2.61) $\quad(-0.07)$

$\mathbf{0 . 0 0 9}^{* *} \quad-0.003$

$(2.40) \quad(-0.33)$

$\mathbf{0 . 0 3 2}^{* * *} \quad-0.007$

(3.80) $\quad(-0.42)$

$\mathbf{0 . 0 2 7}^{* * *} \quad-0.002$

(3.11) $\quad(-0.13)$

$\mathbf{0 . 0 0 5}^{* *} \quad-0.000$

(2.37) $\quad(-0.02)$

$0.003^{*}$

(1.83)

$-0.001$

$(-0.27)$
$-581.95$

$-550.5$

2245 Binary probit

2139 Binary probit

$-612.48$

2245 Binary probit

$-572.45$

2139 Binary probit

$-414.29$

2245 Binary probit

$-527.87$

2245 Binary probit

$-721.78$

2245

Binary probit

$-684.05$

2139

Binary probit

$-197.79$

2240 Binary probit
$-197.79$

$-179.13$

2134

Binary probit

Note: The estimated marginal effects are listed with $\mathrm{z}$ values in parentheses. Control variables include: the degree of risk aversion, age, gender, education, household income, household real asset holding, household financial asset holding. *, **,** represent statistical significance at the $10 \%, 5 \%$, and $1 \%$ levels, respectively. 
Table 6

The marginal effects on debt holding: Estimation with the present bias dummy.

Present bias $(\alpha>0)=1$

Impatience $(\rho) \quad$ Sign effect $(\theta)$ Log pseudolikelihood \#obs Regresson methods Panel A. Overall debt holding

\begin{tabular}{|c|c|c|c|c|c|c|c|c|}
\hline \multirow[t]{3}{*}{ Prob. of being a debtor } & (A) & \multicolumn{2}{|c|}{$\begin{array}{l}\mathbf{0 . 0 3 8} \\
(2.20)\end{array}$} & \multirow[t]{2}{*}{$\begin{array}{l}\mathbf{0 . 0 5 6} \\
(4.72)\end{array}$} & \multirow[t]{2}{*}{$\begin{array}{l}-\mathbf{0 . 0 6 3} \\
(-2.81)^{* * *}\end{array}$} & \multirow[t]{2}{*}{-1032.07} & \multirow[t]{2}{*}{2245} & \multirow[t]{2}{*}{ Binary probit } \\
\hline & & Naifs & Sophisticates & & & & & \\
\hline & (B) & $\begin{array}{l}\mathbf{0 . 0 4 7}^{\text {*** }} \\
(2.29)^{4}\end{array}$ & $\begin{array}{l}0.013 \\
(0.56)\end{array}$ & $\begin{array}{l}\mathbf{0 . 0 5 9} \\
(4.87)\end{array}$ & $\begin{array}{l}-\mathbf{0 . 0 6 1} \\
(-2.69)\end{array}$ & -970.79 & 2139 & Binary probit \\
\hline \multirow[t]{3}{*}{ Debt amounts (in JPYmillion) } & (A) & \multicolumn{2}{|c|}{$\begin{array}{c}0.07 \\
(1.27)\end{array}$} & $\begin{array}{l}\mathbf{0 . 1 9} \\
(4.86)\end{array}$ & $\begin{array}{l}-\mathbf{0 . 2 3} \\
(-2.99)^{* * *}\end{array}$ & -3950.81 & 2245 & Interval tobit \\
\hline & & Naifs & Sophisticates & & & & & \\
\hline & (B) & $\begin{array}{c}\mathbf{0 . 1 1}^{*} \\
(1.76)\end{array}$ & $\begin{array}{c}-0.01 \\
(-0.15)\end{array}$ & $\mathbf{0 . 2 0}^{* * *}$ & $\begin{array}{l}-0.23 \\
(-2.95)^{* * *}\end{array}$ & -3704.62 & 2139 & Interval tobit \\
\hline \multirow[t]{3}{*}{$\begin{array}{l}\text { Debt amounts in the debtor sample } \\
\text { (in JPYmillion) }\end{array}$} & (A) & \multicolumn{2}{|r|}{$\begin{array}{c}0.08 \\
(1.28)\end{array}$} & $\begin{array}{l}0.23^{* * *} \\
(5.00)\end{array}$ & $\begin{array}{l}-0.26 \\
(-3.17)^{* * *}\end{array}$ & -3950.81 & 2245 & Interval tobit \\
\hline & & Naifs & Sophisticates & & & & & \\
\hline & (B) & $\begin{array}{c}\mathbf{0 . 1 4}^{*} \\
(1.78)\end{array}$ & $\begin{array}{c}-0.01 \\
(-0.15)\end{array}$ & $\begin{array}{l}0.25^{* * *} \\
(5.18)^{*}\end{array}$ & $\begin{array}{l}-\mathbf{0 . 2 6} \\
(-3.14)^{* * *}\end{array}$ & -3704.62 & 2139 & Interval tobit \\
\hline \multicolumn{9}{|l|}{ Panel B. Debt purposes } \\
\hline \multicolumn{9}{|l|}{ Prob. of having debts for: } \\
\hline \multirow[t]{3}{*}{ Cars } & (A) & \multicolumn{2}{|c|}{$\begin{array}{l}0.013 \\
(1.29)\end{array}$} & $\begin{array}{l}\mathbf{0 . 0 1 3} \\
(2.02)\end{array}$ & $\begin{array}{l}-\mathbf{0 . 0 5 1} \\
(-3.36)^{* * *}\end{array}$ & -497.81 & 2245 & Binary probit \\
\hline & & Naifs & Sophisticates & & & & & \\
\hline & (B) & $\begin{array}{l}0.006 \\
(0.54)\end{array}$ & $\begin{array}{l}0.001 \\
(0.76)\end{array}$ & $\begin{array}{l}\mathbf{0 . 0 1 2}^{*} \\
(1.91)\end{array}$ & $\begin{array}{l}-\mathbf{0 . 0 4 6} \\
(-3.05)\end{array}$ & -461.18 & 2139 & Binary probit \\
\hline \multirow[t]{3}{*}{ Other goods } & (A) & \multicolumn{2}{|r|}{$\begin{array}{l}0.013 \\
(1.38)\end{array}$} & $\begin{array}{l}\mathbf{0 . 0 1 7} \\
(2.78)\end{array}$ & $\begin{array}{l}-0.018 \\
(-1.40)\end{array}$ & -570.40 & 2245 & Binary probit \\
\hline & & Naifs & Sophisticates & & & & & \\
\hline & (B) & $\begin{array}{l}\mathbf{0 . 0 2 2}^{*} \\
(1.92)\end{array}$ & $\begin{array}{l}0.002 \\
(0.13)\end{array}$ & $\begin{array}{l}\mathbf{0 . 0 1 9} \\
(2.99)\end{array}$ & $\begin{array}{l}-\mathbf{0 . 0 2 3} \\
(-1.70)\end{array}$ & -538.76 & 2139 & Binary probit \\
\hline \multirow[t]{3}{*}{ Living costs } & (A) & \multicolumn{2}{|r|}{$\begin{array}{l}0.004 \\
(1.31)\end{array}$} & $\begin{array}{l}0.003 \\
(1.37)\end{array}$ & $\begin{array}{l}-0.008 \\
(-1.36)\end{array}$ & -307.45 & 2245 & Binary probit \\
\hline & & Naifs & Sophisticates & & & & & \\
\hline & (B) & $\begin{array}{l}0.009 \\
(1.58)\end{array}$ & $\begin{array}{l}-0.002 \\
(-0.38)\end{array}$ & $\begin{array}{l}0.004 \\
(1.36)\end{array}$ & $\begin{array}{l}-0.008 \\
(-1.34)\end{array}$ & -291.42 & 2139 & Binary probit \\
\hline \multirow[t]{3}{*}{ Business } & (A) & \multicolumn{2}{|c|}{$\begin{array}{l}0.001 \\
(0.25)\end{array}$} & $\begin{array}{l}\mathbf{0 . 0 0 6} \\
(2.92)\end{array}$ & $\begin{array}{c}-0.002 \\
(-0.33)\end{array}$ & -172.45 & 2245 & Binary probit \\
\hline & & Naifs & Sophisticates & & & & & \\
\hline & (B) & $\begin{array}{l}0.001 \\
(0.15)\end{array}$ & $\begin{array}{l}-0.000 \\
(-0.04)\end{array}$ & $\begin{array}{l}\mathbf{0 . 0 0 6} \\
(2.56)\end{array}$ & $\begin{array}{l}-0.003 \\
(-0.56)\end{array}$ & -157.55 & 2139 & Binary probit \\
\hline \multirow[t]{3}{*}{ Amusements } & (A) & \multicolumn{2}{|r|}{$\begin{array}{l}\mathbf{0 . 0 0 7}^{*} \\
(1.83)\end{array}$} & $\begin{array}{l}0.003 \\
(1.43)\end{array}$ & $\begin{array}{l}-0.000 \\
(-0.10)\end{array}$ & -159.14 & 2245 & Binary probit \\
\hline & & Naifs & Sophisticates & & & & & \\
\hline & (B) & $\begin{array}{l}\mathbf{0 . 0 0 8}^{* *} \\
(1.98)^{*}\end{array}$ & $\begin{array}{l}0.001 \\
(0.32)\end{array}$ & $\begin{array}{l}0.002 \\
(1.26)\end{array}$ & $\begin{array}{l}0.000 \\
(0.05)\end{array}$ & -139.40 & 2139 & Binary probit \\
\hline
\end{tabular}

Note: The estimated marginal effects are listed with $\mathrm{z}$ values in parentheses. Control variables include: the degree of risk aversion, age, gender, education, household income, household real asset holding, household financial asset holding. *, **, *** represent statistical significance at the $10 \%, 5 \%$, and $1 \%$ levels, respectively. 
Table 7

The marginal effects on overborrowing inclination: Estimation with the present bias dummy.

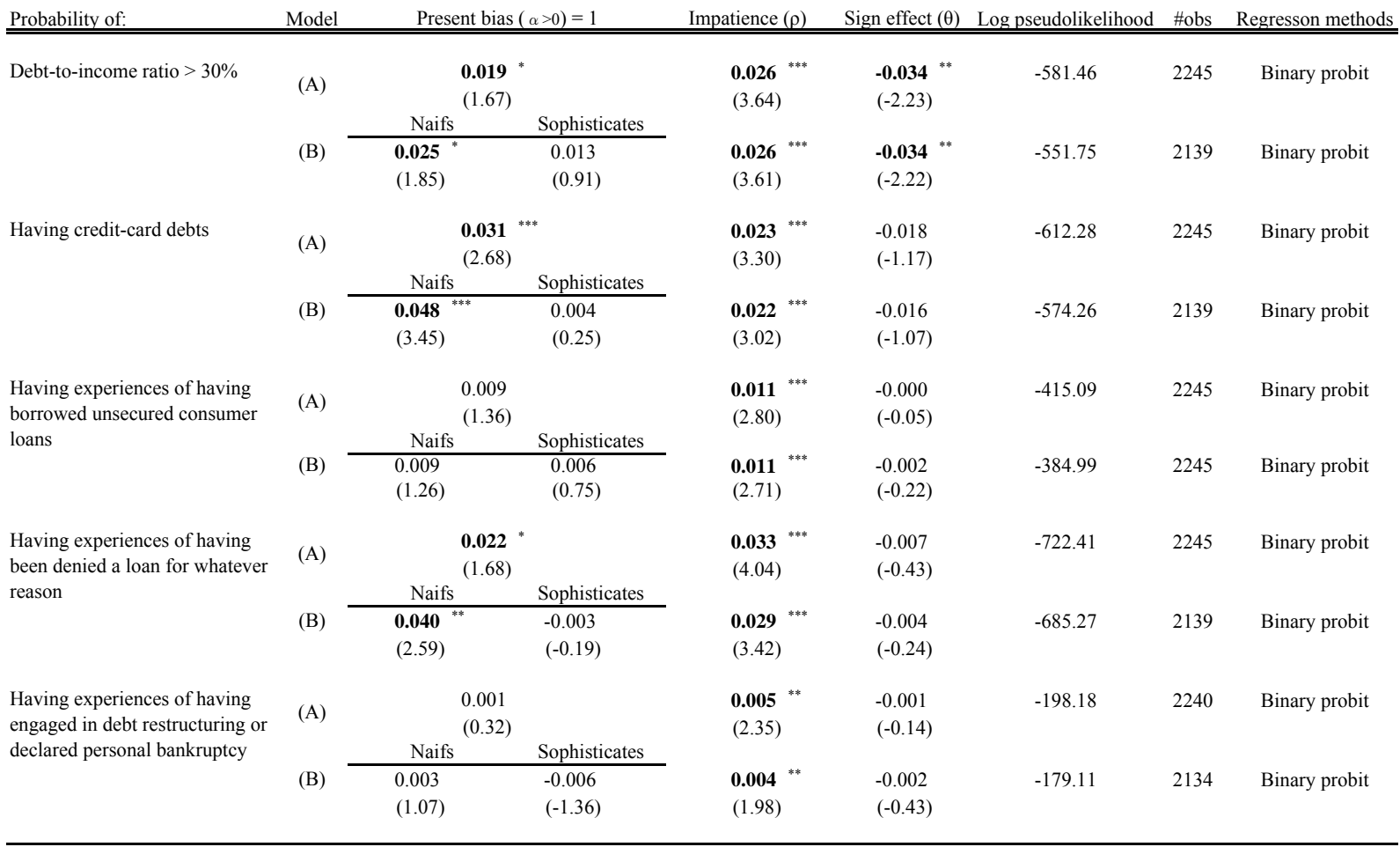

Note: The estimated marginal effects are listed with z values in parentheses. Control variables include: the degree of risk aversion, age, gender, education, household income, household real asset holding, household financial asset holding. *, **, *** represent statistical significance at the $10 \%, 5 \%$, and $1 \%$ levels, respectively. 
Table 8

The marginal effects of time discounting on debt holding and overborrwoing inclination: Credit-constrained respondents excluded from the sample.

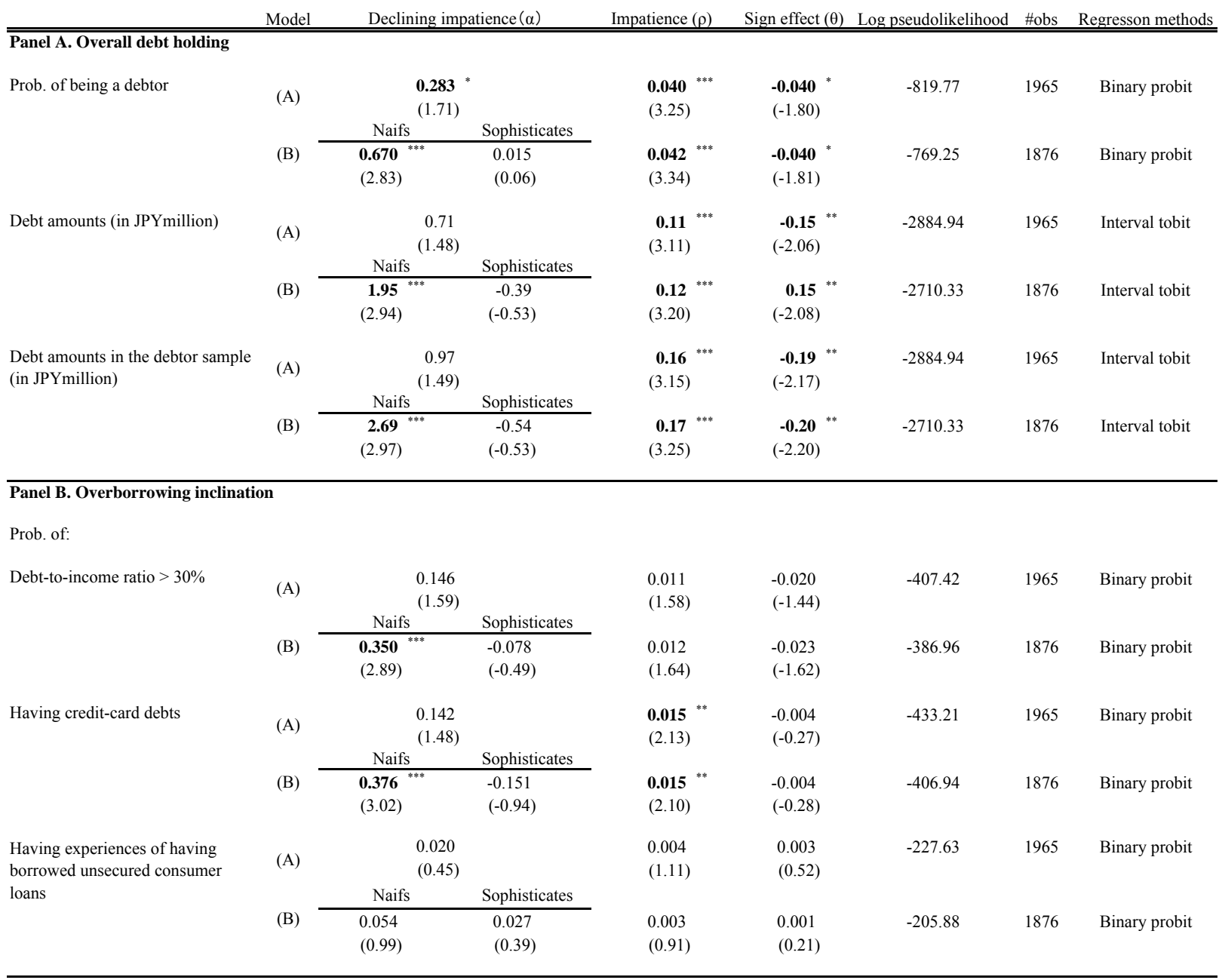

Note : In regressions, any respondent with a credit problem or a troubled credit history (having borrowed to pay off other debts, having the experience of having engaged in debt restructuring or declared personal bankruptcy, or having the experience of having been denied a loan for what ever reason) is excluded from the sample. The estimated marginal effects are listed with z values in parentheses. Control variables include: the degree of risk aversion, age, gender, education, household income, household real asset holding, household financial asset holding. ${ }^{*}, * *, * *$ represent statistical significance at the $10 \%, 5 \%$, and $1 \%$ levels, respectively. 


\section{Figure 1}

Declining discount rates under generalized hyperbolic discounting.

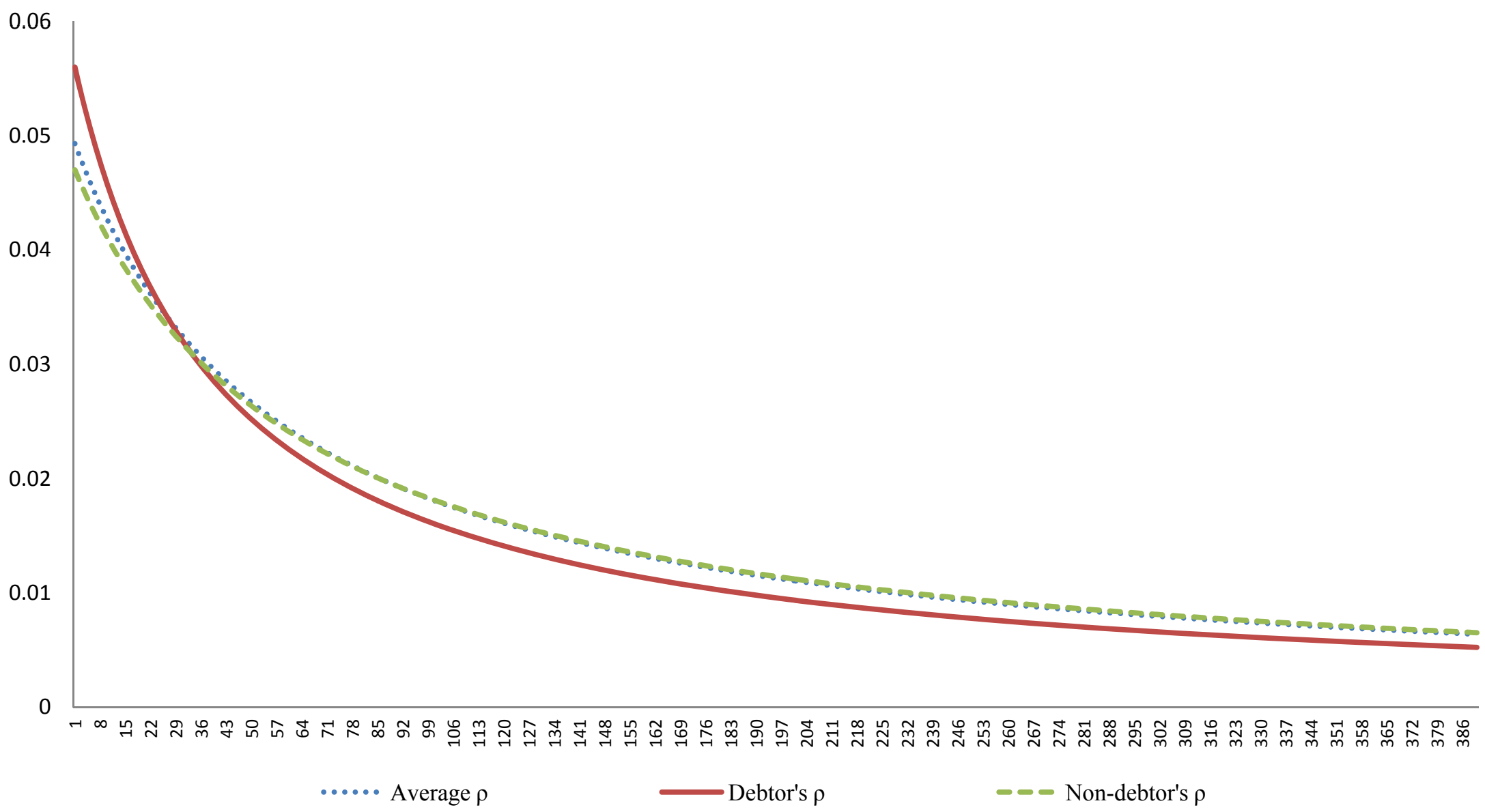

Note: The schedules depict discount rates $\rho=\alpha \eta /(1+\alpha \tau)$ of average respondents, average debtors, and average non-debtors, where the ( $\alpha$, $\eta)$ values are the sample means of the corresponding samples: $(0.018,2.842)$ for average respondents; $(0.018,2.240)$ for average debtors; and $(0.016,2.938)$ for average non-debtors. 


\section{Figure A1}

Questions to elicit the generalized hyperbolic discount factor.

Q1 (Questions on discount rates for immediate future)

Which one do you prefer? Choos one you prefer.

(A) To get JPY 1,000 today.

(B) To get JPY 3,000 a week later.
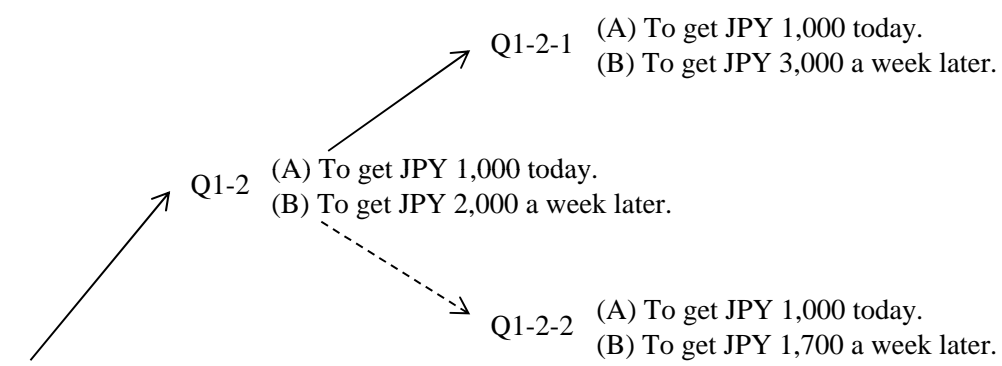

(A) To get JPY 1,000 today.

(B) To get JPY 2,000 a week later.

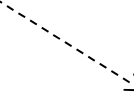

Q1-2-2 (A) To get JPY 1,000 today.

(B) To get JPY 1,700 a week later.

Q1-1 (A) To get JPY 1,000 today.

(B) To get JPY 1,500 a week later.

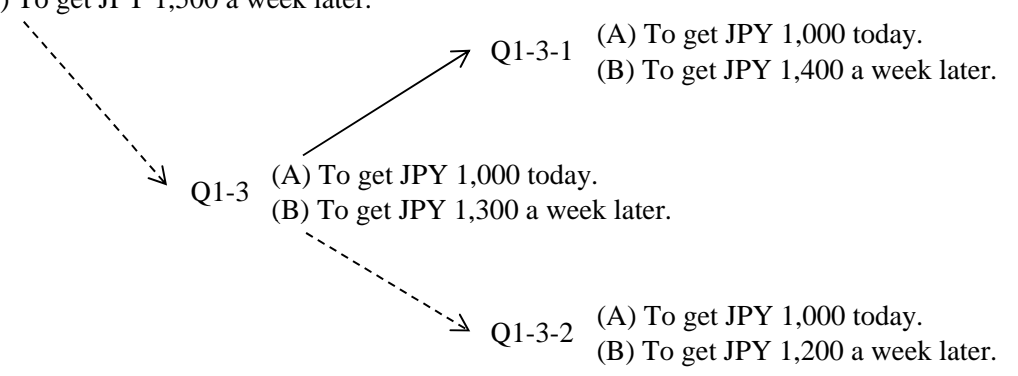

Q2 (Question on discount rates for distant future)

Which one do you prefer? Choos one you prefer.

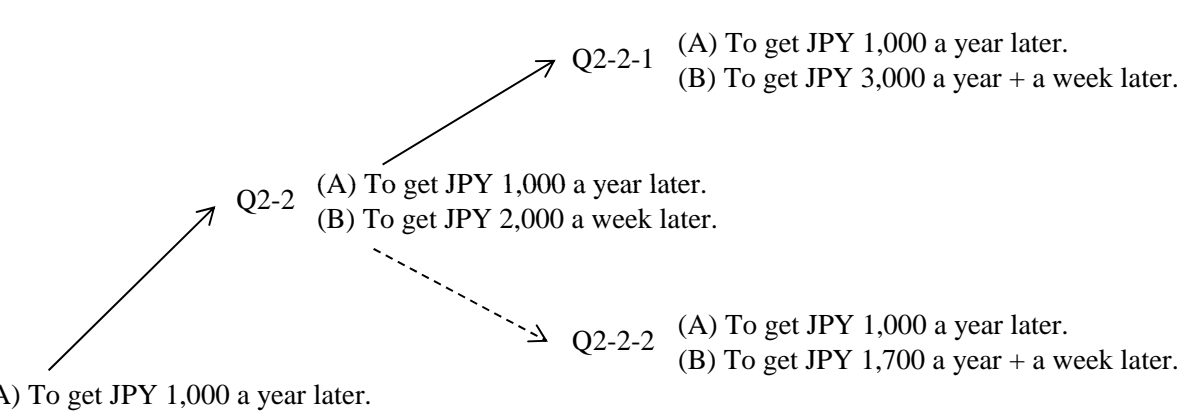

Q2-1 (A) To get JPY 1,000 a year later.

(B) To get JPY 1,500 a year + a week later.

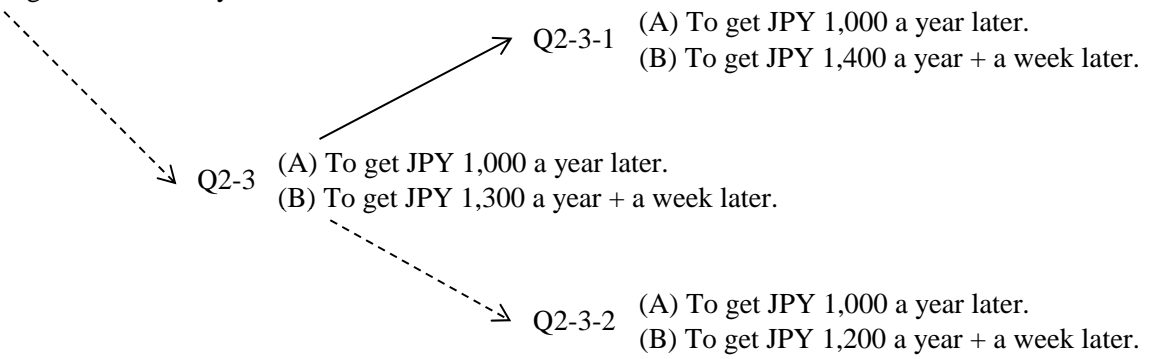

